\title{
MECHANISMS OF GAS PERMIEATION THROUGH POLYMER MEMBRANES
}

\author{
(Contract No. DE-EG02-87ER 13649)
}

\section{SUMMARY TECHNICAL REPOR'T}

for Period September 1991 - August 1992

by

\section{S. Alexander Stern}

Department of Chemical Engineering and Materials Science

Syracuse University, Syracuse, NY 13244

(315) $443-4469$

Prepared for:

\section{U.S. DEPARTMENT OF ENERGY}

\section{OFFICE OF BASIC ENERGY SCIENCES DISCLAIMER}

\footnotetext{
This report was prepared as an account of work sponsored by an agency of the United States Government. Neither the United States Government nor any agency thereof, nor any of their employees, makes any warranty, express or implied, or assumes any legal liability or responsibility for the accuracy, completeness, or usefulness of any information, apparatus, product, or process disclosed, or represents that its use would not infringe privately owned rights. Reference herein to any specific commercial product, process, or service by trade name, tradernark, manufacturer, or otherwise does not necessarily constitute or imply its endorsement, recommendation, or favoring by the United States Government or any agency thereof. The views . opinions of authors expressed herein do not necessarily state or reflect those of the l wited States Convernment or any agency thereof. 


\section{SUMMARY}

Progress is reported in the following two areas:

\section{The Concentration-Temperature Superposition Principle (CTSP)}

The permeation of gases through nonporous polymer membranes is known to occur by a "solution-diffusion" mechanism. The solubility and diffusivity of gases in glassy polymers, and hence also the gas permeability of the polymers, are commonly nonlinear functions of the penetrant gas pressure (or concentration in the polymers). The CTSP is a new theor'tical model developed in this laboratory to describe the gas solubility in glassy polymers in cases where the polymer is significantly plasticized (swelled) by the penetrant gas. The effect of plasticization is to lower the glass-transition temperature, $\mathrm{Tg}$ of the penetrant/polymer system, thereby altering the dependence of the gas solubility on the gas pressure. The CTSP is based on concepts derived from the viscoelasticity of polymers. The description of the gas solubility in plasticized glassy polymers derived from the CTSP is validated by a variety of experimental measurements.

The CTSP has been extended to describe the dependence of the gas diffusivity in plasticized glassy polymers, and also for the gas permeability of such polymers, on the penetrant pressure (or concentration in the polymers). A further extension of the CTSP to the diffusion and permeation of gas mixtures in such polymers is being studied. Experimental data must be generated to test the validity of these formulations over a sufficiently wide range of penetrant pressure (or concentrations).

\section{The Solubility of gases in Poly(Alkyl Methacrylates)}

The objective of this study was to determine the dependence of the gas solubility in glassy polymers on the "excess" free volume of such polymers. The excess free volume is a 
consequence of the nonequilibrium state of glassy polymers. The dependence of the gas solvoility in glassy polymers on the penetrant pressure, when the polymer is not significantly plasticized (swelled) by the penetrant, can be satisfactorily described by the "dual-mode sorption" model. The "Langmuir capacity" constant, $c_{H}^{\prime}$, in this model is related to the excess free volume. Poly(alkyl methacrylates) have been reported to have a lower excess free volume than other polymers with comparable glass-transition temperatures, $\mathrm{Tg}$ [except for poly(methy] methacrylate)]. Hence, it was desired to determine whether the values of $c_{H}^{\prime}$ for gases in poly(alkyl methacrylates) are also lower than found for other glassy polymers under comparable conditions.

Accordingly, the solubility of $\mathrm{CH}_{4}$ in poly(ethyl methacrylate) (PEMA) and in poly(n-butyl methacrylate) (PnBMA) was measured over a range of temperatures and at pressures up to about 35 atm. It was found that the $C_{H}^{\prime}$ values for $\mathrm{CH}_{4}$ in PEMA and PnBMA do not reflect a lower excess free volume. The $c_{H}^{\prime}$ values for $\mathrm{CH}_{4}$ in PEMA and PnBMA, as well as of a variety of other glassy polymers, can be related at any temperature $\mathrm{T}(<\mathrm{Tg})$ to their glass-transition temperature, $\mathrm{Tg}$, by the expression:

$$
C_{H}^{\prime}=k(1-T / T g)
$$

where $\mathrm{k}$ is a constant. A similar relation was found for $\mathrm{CO}_{2}$ in a variety of glassy polymers, using data reported in the literciture. The fact that this expression is applicable to many different glassy polymers including PEMA and PnBMA suggests that the excess free volume of poly(alkyl methacrylates) is not very different from that in other glassy polymers. This may be due to the fact that poly(alkyl methacrylates) exhibit sub-Tg transitions and hence additional free volume is created below their $\mathrm{Tg}$.

The solubility of $\mathrm{C}_{2} \mathrm{H}_{6}$ in PnBMA was also measured at several temperatures and at 
pressures up to $30 \mathrm{~atm}$. However, PnBMA was found to be markedly plasticized by $\mathrm{C}_{2} \mathrm{H}_{6}$, so that these data must be treated by a suitable modification of the dual-mode sorption model. 


\section{TABLE OF CONTENTS}

Page

I. THE CONCENTRATION-TEMPERATURE SUPERPOSITION PRINCIPLE $\ldots \ldots$. 1

A. GENERAL CONSIDERATIONS $\ldots \ldots \ldots \ldots \ldots \ldots \ldots$

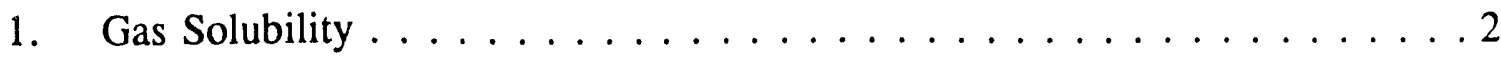

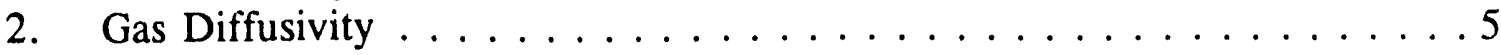

3. Gas Permeability ................... 6

B. RELATED STUDIES $\ldots \ldots \ldots \ldots \ldots$

References

II. THE SOLUBILITY OF GASES IN POLY(ALKYL METHACRYLATES) . . . . . 15

A. GENERAL CONSIDERATIONS $\ldots \ldots \ldots \ldots \ldots \ldots$

1. Gas Solubility in Glassy Polymers . . . . . . . . . . . . . . 15

2. The "Excess" Free Volume in Glassy Polymers $\ldots \ldots \ldots \ldots \ldots$

3. Dependence of Langmuir Capacity Constant, $C_{H}^{\prime}$ on the Excess Free Volume . . . . . . . . . . . . . . 16

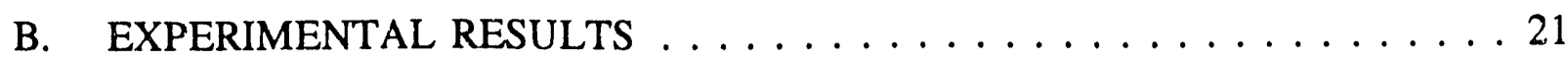

C. DISCUSSION OF RESULTS $\ldots \ldots \ldots \ldots \ldots \ldots$

References

III. PUBLICATIONS RESULTING FROM STUDIES SPONSORED BY THE OFFICE OF BASIC ENERGY SCIENCES . . . . . . . . . . . 35 


\section{THE CONCENTRATION-TEMPERATURE SUPERPOSITION PRINCIPLE}

\section{A. GENERAL CONSIDERATIONS}

The concentration-temperature superposition principle (CTSP) is a new concept developed in this laboratory to describe the solubility and diffusivity of gases in glassy polymers in cases where the polymers are significantly plasticized (swelled) by the penetrant gases $(1,2)$. Relations based on the CTSF can represent satisfactorily the dependence of the solubility and the diffusivity on the penetrant pressure, or concentration in the polymers, over wide ranges of these variables. The effect of polymer plasticization on the gas solubility and diffusivity is taken into consideration in these relations by means of a modified Doolittle (WLF) equation $(3,4)$. The formulation of the gas solubility and diffusivity in plasticized glassy polymers, based on the CTSP, is validated by a variety of experimental data reported in the literature $(1,2)$ as well as by data generated in this laboratory.

During the past report period, the CTSP was extended to describe also the permeation of gases through glassy polymer membranes which are plasticized by the penetrant gases. More specifically, a new relation was derived to represent the dependence of permeability coefficients for such gas/polymer systems on the penetrant gas pressure. This relation should prove useful for the mathematical modeling of a variety of membrane processes for the separation of gas mixtures containing one or more components which plasticize glassy polymer membranes, e.g., $\mathrm{CO}_{2}$ and higher hydrocarbons in natural gas. Glassy polymer membranes are widely used in membrane separation processes of industrial interest because of their high gas selectivity.

The new representations of gas solubility and diffusivity in glassy polymers, and of gas permeation through glassy polymer membranes, complements the well-known "dual-mode sorption" model (5-9). This model is being widely used to describe the solubility and tr insport 
(by diffusion and permeation) of gases in glassy polymers in cases where the polymers are not significantly plasticized by the penetrant gases.

The new relation describing the permeability behavior of plasticizing gases and gas mixtures in glassy polymers, which was derived from the CTSP, is discussed below. The gas solubility and diffusivity relations are also presented to show how the permeability relation was obtained.

\section{Gas Solubility}

The solubility of gases in glassy polymers, i.e., at temperatures below the glass-transition temperature, $\mathrm{Tg}$, of the polymers, is a strongly nonlinear function of the gas pressure. Thus, isothermal plots of the gas concentration $c$ (the solubility) in glassy polymers as a function of the pressure $p$ at solution equilibrium are commonly concave to the pressure axis. When the polymers are strongly plasticized (swelled) by the penetrant gas, the isotherms exhibit an inflection point at some sufficiently high pressure and become linear as the pressure is further increased. Moreover, the linear segment of the solubility isotherms extrapolates to the origin of the $c$ versus $p$ plots, cf. Figures 1 and 2 .

The above solubility bchavior has been attributed to the fact that the glass-transition temperature, $\mathrm{Tg}$, of the polymers is depressed by a plasticizing penetrant gas to an extent which depends on the penetrant concentration. The depression of Tg causes, in turn, a decrease in the gas solubility. The infiection point in the solubility isotherm (cf. Figures 1 and 2 ) indicates the

penetrant pressure (or concentration in the polymer) at which the $\mathrm{Tg}$ is depressed to the temperature of the isotherm, i.e., at which a transition occurs from the glassy to the "rubbery" 


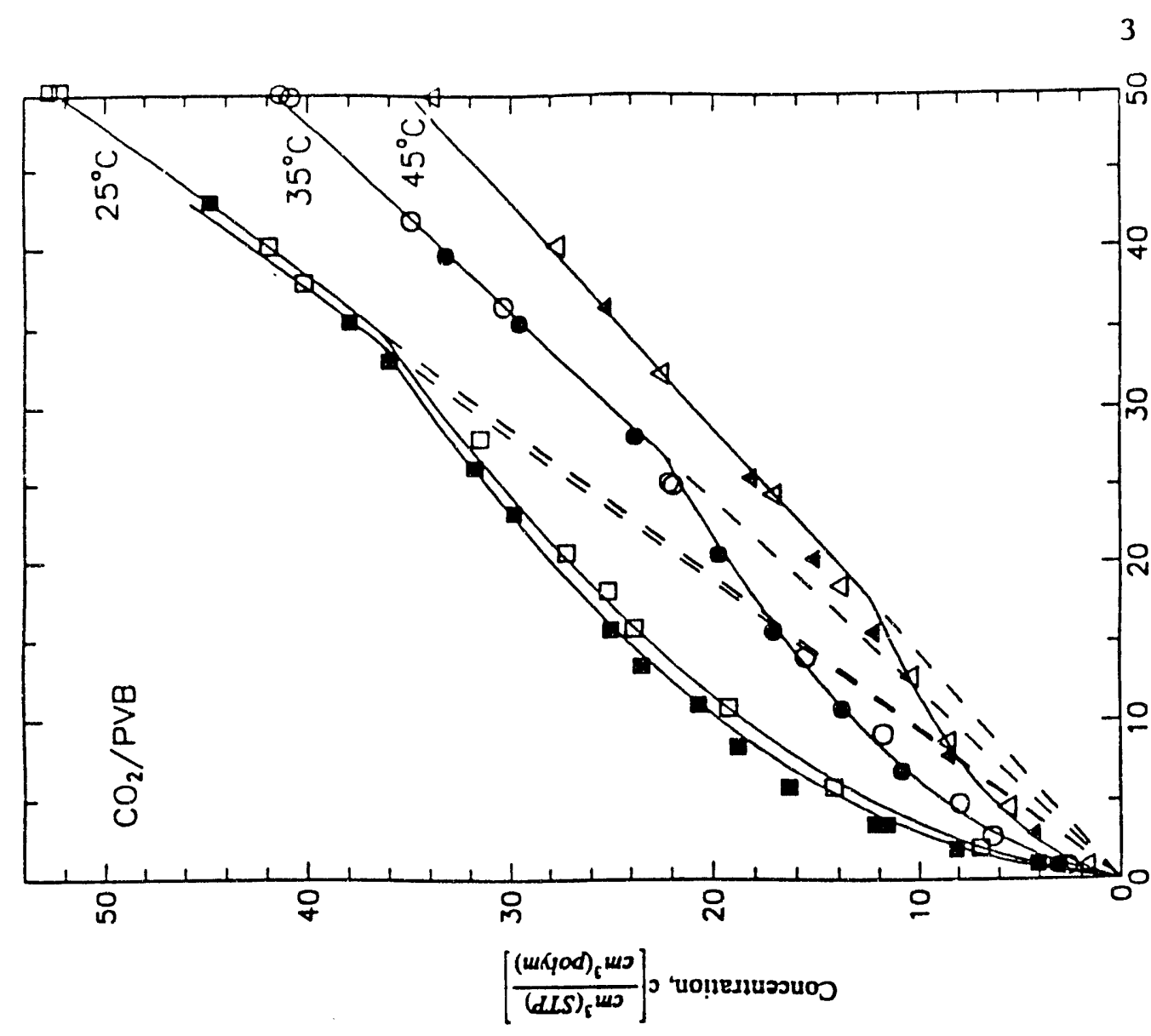

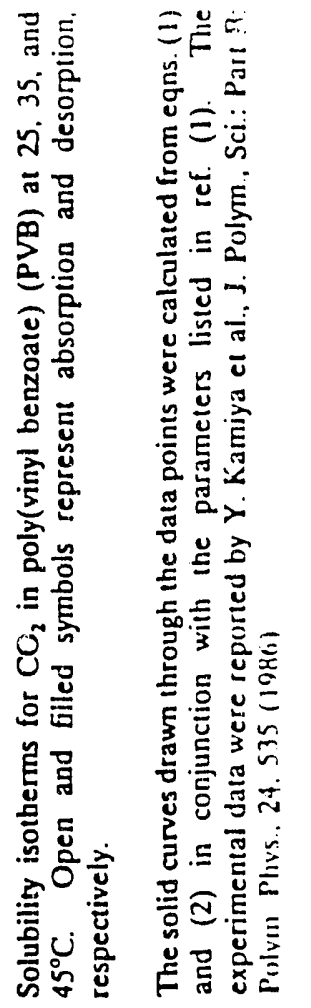

产

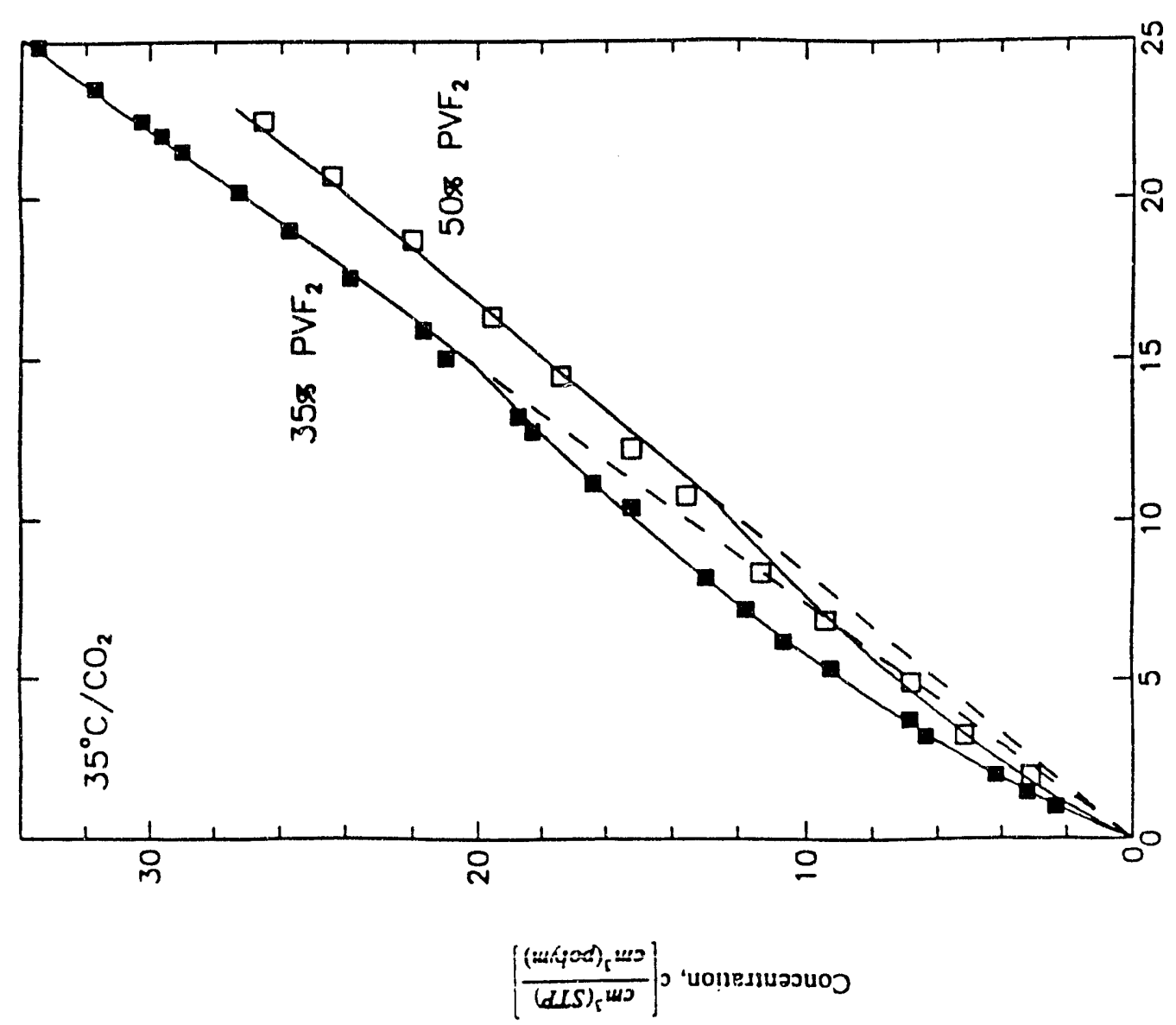

$\Xi_{0}$ 
polymer state. At higher pressures (or concentrations) the solubility isotherm becomes linear because the solubility of many gases in rubbery polymers obeys Henry's law. At even higher pressures (or penetrant concentrations in the polymer) it is predicted that the isotherm will become convex to the pressure axis because of the plasticization of the polymer in its rubbery state.

Our new solubility model based on the concentration-temperature superposition principle (CTSP) describes quantitatively the entire isotherm, including its inflection point and linear section, by means of the equation (1):

$$
c=S(0) \alpha_{r}(c) \cdot p
$$

where $S(0)$ is a solubility coefficient in the Henry's law limit $(c \rightarrow 0)$, and $\alpha_{\tau}(c)$ is a "concentration shift factor" defined by the relation:

$$
\log a_{r}(c)=A\left[\frac{\Gamma g(c)[T g(c)-T g(0)]}{[T g(0)]^{2}}\right][T g(0)-T],
$$

where $\dot{A}$ is a characteristic constant; $T$ is the absolute temperature; $\operatorname{Tg}(0)$ is the glass-transition temperature of the pure polymer $(c \rightarrow 0)$; and $\operatorname{Tg}(\mathrm{c})$ is the glass-transition temperature of the polymer containing a dissolved penetrant at concentration $c$. $\operatorname{Tg}(\mathrm{c})$ can be estimated from the relation of Chow (10). It should be noted that eqns. (1) and (2), when combined, contain only two parameters, namely, $A$ and $S(0)$.

The derivation of eqns. (1) and (2) is described in ref. (1), which is attached. The solubility coefficient, $S$, for a plasticizing gas in a glassy polymer is obtained from eqn. (1): 


$$
S \equiv c / p=S(0) a_{r}(c)
$$

where the symbols are as used before. The shift factor $\alpha_{\tau}(\mathrm{c})$ is given by eqn. (2).

It was shown previously that eqns. (1) and (2) describes very satisfactorily the dependence of the $\mathrm{CO}_{2}$ solubility in poly(ethylene terephthalate), in blends of poly(vinylidene fluoride) and poly(methyl methacrylate), and in poly(vinyl benzoate), cf. ref (1) attached. Equations (1) and (2) also describe well the solubility of $\mathrm{C}_{2} \mathrm{H}_{6}$ in poly(ethyl methacrylate) and in poly(vinyl benzoate); these data were obtained in our laboratory.

\section{Gas Diffusivity}

It has been shown that the CTSP can also be used to describe the diffusion of gases in glassy polymers in cases where the polymer is strongly plasticized by the penetrant gas. The mutual diffusion coefficient, $D(c)$, is then given by the relation

$$
D(c)=D(0) \exp \left\{-A_{D}\left[\frac{T g(c)[T g(c)-T g(0)]}{[T g(0)]^{2}}\right][T g(0)-T]\right\}
$$

where $D(0)$ is the diffusion coefficient at zero penetrant concentration $(c \rightarrow 0), A_{D}$ is a characteristic constant, and all the other symbols are as defined before. Equation (4) is applicable to a specified constant temperature $\mathrm{T}$ and contains only two adjustable parameters, $D(0)$ and $A_{D}$. These parameters can be determined by fitting eqn. (4) to experimental diffusion data for a range of penetrant concentrations in a polymer. $\operatorname{Tg}(0)$ can be determined by differential scanning calorimetry or thermomechanical analysis, and $\operatorname{Tg}(\mathrm{c})$ can be estimated from Chow's relation (10).

Equation (4) describes satisfactorily the dependence of the mutual diffusion coefficient, 
$\mathrm{D}(\mathrm{c})$, on the concentration of $\mathrm{CO}_{2}$ in polyarylate and in polycarbonate (2). However, with the exception of $\mathrm{CO}_{2}$ in polycarbonate at $85^{\circ} \mathrm{C}$, these data were not obtained over a sufficiently wide range of $\mathrm{CO}_{2}$ concentrations in the polymers (or $\mathrm{CO}_{2}$ pressures) to lower the $\mathrm{Tg}$ of the $\mathrm{CO}_{2}$ /polymer systems to the experimental temperature $(11,12)$. In other words, the transition from the glassy to the rubbery polymer state was not reached. Therefore, diffusivity data over wider ranges of penetrant gas concentration are required to test more rigorously the validity of eqn. (4).

The predicted dependence of the mutual diffusion coefficient, $D(c)$, on the penetrant gas concentration, $\mathrm{c}$, is shown graphically in Figure 3 for a hypothetical penetrant/polymer system; the polymer is assumed to be strongly plasticized by the penetrant gas. The discontinuities in the plots of Figure 3 occur at penetrant concentrations at which the glass-transition temperature of the penetrant/polymer system is depressed to the indicated (experimental) temperature. Experimental data must be generated to test the validity of eqn. (4).

\section{Gas Permeability}

The gas permeability of polymer membranes is characterized by a mean permeability coefficient, $\bar{P}$, which is defined by the isothermal relation $(6,7,13,14)$ :

$$
\bar{P}=\frac{J_{s} \cdot \delta}{p_{h}-p_{l}}
$$

where $\bar{P}$ is a mean permeability coefficient, $\mathrm{J}_{\mathrm{s}}$ is the steady-state rate of gas permeation through a membrane of effective thickness $\delta$ when the gas pressures $\mathrm{p}_{h}$ and $\mathrm{p}_{l}\left(<\mathrm{p}_{h}\right)$ are applied at opposite membrane interfaces. It can be shown that $\bar{P}$ can be expressed in terms of a mean 


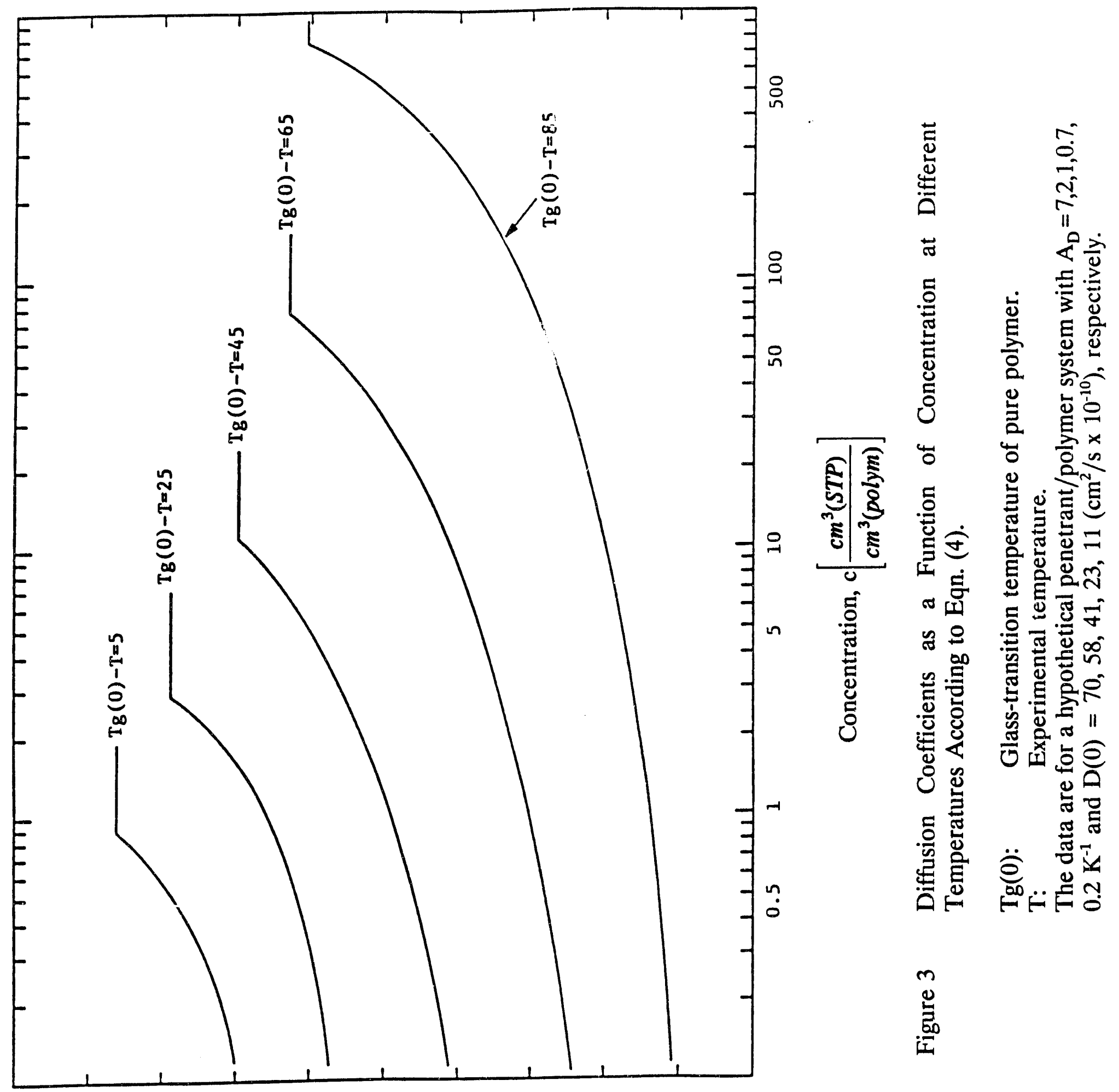

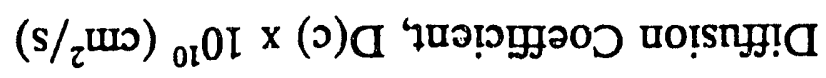


diffusion coefficient, $\bar{D}$, and of a solubility coefficient, $\mathrm{S}_{h}$ :

$$
\bar{P}=\bar{D} \cdot S_{h} ;
$$

where $S_{h}=c_{h / p} h ; c_{h}$ is the concentration of the penetrant gas dissolved at the "upstream" (highpressure) interface of the membrane when a gas pressure $\mathrm{p}_{h}$ is applied at that interface. The mean diffusion coefficient, $\bar{D}$, is defined by the relation:

$$
\bar{D}=\int_{c_{1}}^{c_{h}} D(c) d c /\left(c_{h}-c_{1}\right)
$$

where $\mathrm{D}(\mathrm{c})$ is the mutual diffusion coefficient; $c_{h}$ and $c_{l}\left(<c_{h}\right)$ are the concentrations of penetrant gas dissolved at opposite membrane interfaces when the gas pressures $\mathrm{p}_{h}$ and $\mathrm{p}_{l}\left(<\mathrm{p}_{h}\right)$ a. ipplied at those interfaces.

Equations (3), (6), and (7) then yield the expression:

$$
\bar{P}=\left[\int_{c_{1}}^{c_{h}} D(c) d c /\left(c_{h}-c_{1}\right)\right] S(0) a_{T}\left(c_{h}\right) .
$$

where $\alpha_{T}$ and $D(c)$ are given by eqns. (2) and (4), respectively. The above relation has four parameters, namely, $A, S(0), A_{D}$, and $D(0)$; the parameters $A$ and $S(0)$ are obtained from solubility measurements, whereas the parameters $A_{D}$ and $D(0)$ are determined from diffusivity measurements. Alternatively, only three parameters are necessary when $P(0)[\equiv D(0) \cdot S(0)]$ is available from permeability measurements at very low penetrant pressures.

The validity of eqn. (8) has not yet been tested experimentally. This equation is being extended to gas mixtures. 


\section{B. RELATED STUDIES}

Alternative representations of the type of solubility isotherms shown in Figures 1 and 2, i.e., for cases where the polymers are strongly plasticized by a penetrant gas, have been proposed by Paul and coworkers $(15,16)$ and by Kamiya et al. $(17)$. Both these representations are based on semi-empirical extensions of the dual-mode sorption model (5-9). As menti d above, this model is being widely used to represent the solubility and transport of gases in glassy polymers in cases where the polymers are not significantly plasticized by the penetrant gases.

In order to describe the nature of the proposed extensions of the dual-mode sorpt it is necessary to summarize the assumptions made by this model insofar as the solubility of gases in glassy polymers is concerned. According to the dual-mode sorption model, gases dissolve in glassy polymers by two concurrent mechanisms:

(a) An ordinary solution in relaxed domains of glassy polymers, similar to the solution of gases in "rubbery" polymers, i.e., at temperatures above the $\mathrm{Tg}$ of the polymers. The concentration, $c_{D}$, of the penetrant gas population dissolved by this mode is related to the penetrant gas pressure, $p$, by Henry's law:

$$
c_{D}=k_{D} p \text {, }
$$

where $k_{D}$ is a solubility coefficient in the Henry's law limit;

(b) Gas absorption at fixed sites in unrelaxed domains of glassy polymers. The fixed sites could be molecular-scale "gaps" or "microvoids" dispersed in the polymer matrix, perhaps trapped between stiffer chain segments as a result of the nonequilibrium nature of the glassy polymer state. The concentration, $c_{H}$, of the penetrant population dissolved at fixed sites is related to the pressure, $\mathrm{p}$, by the Langmuir isotherm: 


$$
c_{H}=c_{H}^{\prime} b p /(1+b p)
$$

where $c_{H}^{\prime}$ is a "Langmuir saturation constant", and b is a "Langmuir affinity" constant. The two types of penetrant populations, i.e., the Henry's law and Langmuir populations, are assumed to be in equilibrium with one another.

The total penetrant concentration, $c$, is then the sum of $c_{D}$ and $c_{H}$; thus, eqns. (9) and (10) yield:

$$
c=c_{D}+c_{H}=k_{D} p+c_{H}^{\prime} b p /(1+b p)
$$

The parameters $\mathrm{k}_{\mathrm{D}}, c_{H}^{\prime}$, and $\mathrm{b}$ decrease with increasing temperature. In particular, $c_{H}^{\prime} \rightarrow 0$ as $\mathrm{T} \rightarrow \mathrm{Tg}$; eqn. (11) then reduces to Henry's law (cf. Figure 4):

$$
c=k_{D} \rho
$$

Equation (11) has been used extensively to correlate and compare the solubility of many gases in a variety of glassy polymers, in cases where the polymers are not significantly plasticized. For example, eqn. (11) can be used to describe the solubility isotherms shown in Figures 1 and 2 at pressures (or penetrant concentrations) well below the inflection points of the isotherms.

In order to describe the entire solubility isotherms shown in Figures 1 and 2, i.e., both the segments concave to the pressure axis and the linear segments, Paul and coworkers $(15,16)$ suggested a more general form of eqn. (11) in which $c_{H}^{\prime}$ is replaced by the semi-empirical function: 


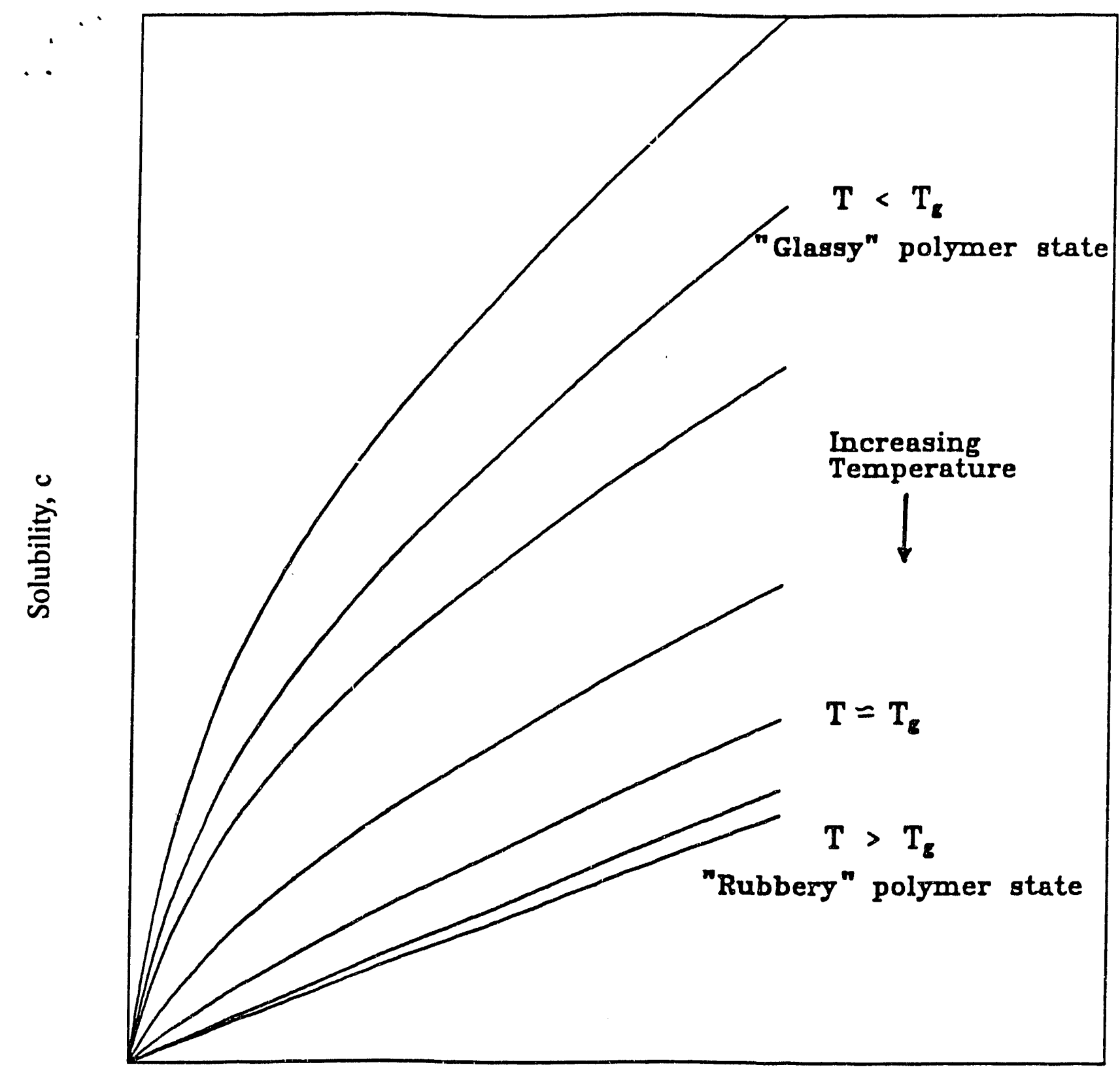

Pressure, $\mathrm{p}$

Figure 4 Illustration of solubility of gases in polymers as a function of penetrant gas pressure above and below the glass-transition temperature, $T_{g}$, of polymers.

"Dual-mode sorption" behavior for $\mathrm{T}<\mathrm{T}_{\mathbf{g}}$ :

$$
c=k_{D} p+c_{B}^{\prime} b p /(1+b p)
$$

Henry's law behavior for $T \geqslant T_{\varepsilon}$ :

$$
c=k_{D} D \quad, \quad\left(c_{B}^{\prime}=0\right)
$$




$$
c_{H}^{\prime}=c_{H O}^{\prime}\left(\frac{T g(c)-T}{T g O-T}\right),
$$

where $c_{H O}^{\prime}$ and Tgo are, respectively, the Langmuir capacity constant and the glass-trausition temperature of the polymer in the absence of any plasticization; $\mathrm{Tg}(\mathrm{c})$ is the glass-transition temperature of the penetrant/polymer system at penetrant concentration c (or pressure p). The value of $T(c)$ can be estimated by the method of Chow (10). Equation (:1) thus becomes:

$$
c=k_{D} p+c_{H o}^{\prime}\left(\frac{T g(c)-T}{T g o-T}\right)\left(\frac{b p}{1+b p}\right) ;
$$

when plasticization is not significant, i.e., when $c \rightarrow 0$, eqn. (14) reduces to eqn. (11).

Kamiya et al. (17) have proposed another se ni-empirical extension of the dual-mode sorption model which contains five parameters and, therefore, is not practical.

Our new representation of gas solubility in glassy polymers based on the "concentrationtemperature superposition principle" (CTSP), cf. eqns. (1) and (2), contains only two parameters and is derives from concepts widely used in visoelasticity studies of polymers. Eqns. (1) and (2) describe satisfactorily both the nonlinear and linear segments of solubility isotherms and locate the inflection point in these isotherms marking the transition from the glassy to the rubbery polymer states due to plasticization (at constant temperature), cf. Figures 1 and 2. Moreover, the CTSP can be extended to describe also the diffusion of plasticizing gases in polymers, and therefore also the permeation of such gases through polymer membranes.

The CTSP does not make any assumptions concerning the heterogeneity of glassy polymers, as does the dual-mode sorption model. Consequently, these two represnetations of gas solubility in glassy polymers complement one another. However, the dual-mode sorption 
model does not appear to have been extended also to the diffusion of gases in glassy polymers, or to the permeation of gases through glassy polymer membranes, in cases where the polymers are strongiy plasticized by the penetrant gases. 


\section{REFERENCES}

1. Y. Mi, S. Zhou, and S.A. Stern, Macromolecules, 24, 2361 (1991).

2. Y. Mi, S.A. Stern, and S. Zhou, In preparation.

3. M.L. Williams, R.F. Landel, and J.D. Ferry, J. Am. Chem. Sco., 77, 3701 (1955).

4. J.D. Ferry, "Viscoelastic Properties of Polymers", 3rd Ed., John Wiley \& Sons, New York, 1980.

5. D.R. Paul, Ber. Bunsenges. Phys. Chem., 포, 294 (1979).

6. H.L. Frisch and S.A. Stern, Crit. Revs. Solid State and Mat. Sci., 11(2), 123 (1987), CRC Press, Boca Raton, FL.

7. W.J. Koros and R.T. Chern, Chap. 20 in "Handbook of Separation Prucess Technology", R.W. Rousseau, Ed., Wiley-Interscience, New York, 1987, pp. 862-953.

8. W.R. Vieth, "Membrane Systems: Analysis and Design", Hanser Publishers, New York, 1988.

9. S.A. Sterna dn S. Trohalaki, Chapt. 2 in "Barrier Polymers and Structures", W.J. Koros, Ed., ACS Symposium Series 423, American Chemical Society, Washington, D.C., 1990, pp. 22-59.

10. T.S. Chow, Mscomolecules, $\underline{13}, 362$ (1980).

11. W.J. Koros and D.R. Paul, J. Polym. Sci., Polym. Phys. Ed., 16, 1947, 2171 (1978).

12. W.J. Koros, Ph.D. Dissertation, Dept. of Chemical Engineering, The University of Texas at Austin, 1977.

13. S.A. Stern and H.L. Frisch, Ann. Revs. Mat. Sci., 11, 523 (1981).

14. S.A. Stern, in "Synthetic Membranes", M.B. Chenoweth, Ed., MMI Press Symposium Series, Vol. 5, Harwood Academic Publishers, New York, 1986, pp. 1-37.

15. J.S. Chiou, Y. Maeda, and D.R. Paul, J. Appl. Polym. Sci., 30, 4019 (1985).

16. J.S. Chiou and D.R. Paul, J. Membrane Sci., 45, 167 (1989).

17. Y. Kamiya, K. Mizoguchi, T. Hirose, and Y. Naito, J. Polym. Sci.: Part B: Polym. Phys., 27, 879 (1989). 


\section{THE SOLUBILITY OF GASES IN POLY(ALKYL METHACRYLATES)}

\section{A. GENERAL CONSIDERATIONS}

\section{Gas Solubility in Glass ${ }^{\prime \prime}$ Polymers}

The solubility behavior of gases in poly(alkyl methacrylates), a homologous series of amorphous glassy polymers, has attracted considerable interest in recent years. Some of these polymers have a much smaller excess free volume in their glassy state than other polymers, as is shown in a following section. Consequently, the study of gas solubility in different poly(alkyl methacrylates) provides new information on the dependence of the solubility on the excess free volume of glassy polymers. Moreover, such a study can also yield a better understanding of the "solution-diffusion" mechanism by whiclı gases permeate in and through glassy polymers (1-6).

The solubility of gases in glassy polymers is commonly a nonlinear function of the pressure of the penetrant gases; the gas solubility is defined here as the concentration $c$ of a gas dissolved in a polymer at a pressure $p$ and temperature $T$ at solution equilibrium. Isothermal plots of $c$ versus $p$ (solubility isotherms) for many gases in glassy polymers are characteristically concave to the pressure axis. Such isotherms are well described by the "dual-mode sorption" model [e.g., refs. (1) to (5)] and can be represented by the relation, cf. Part I of this report:

$$
c=k_{d} p+c_{H}^{\prime} b p /(1+b p) \text {. }
$$

where $k_{\mathrm{D}}$ is a solubility coefficient in the Henry's law limit; $c_{H}^{\prime}$ is the "Langmuir capacity" constant; and $\mathrm{b}$ is the "Langmuir (or site) affinity" constant. The nonlinear dependence of $c$ on $p$ has been attributed to the presence of an "excess" or "unrelaxed" free volume in glassy polymers, possibly dispersed in a polymer matrix in the form of molecular-scale "gaps" or "microvoids", cf. ref. (7). 


\section{The "Excess" Free Volume in Glassy Polymers}

The magnitude of the excess (unrelaxed) free volume of a glassy polymer at a temperature $T$ can be quantified by the difference in the specific volumes $V_{B}-V_{r}$, where $V_{g}$ is the actual specific volume of the polymer, and $V_{r}$ is the hypothetical specific volume of the polymer in a state of thermodynamic equilibrium. $V_{r}$ is obtair ed by extrapolating a plot of the specific volume versus the temperature from above $\mathrm{Tg}$, the glass-transition temperature of the polymer, to the desired temperature T. This is illustrated in Figure 1; it should be noted that the excess free volume vanishes when the temperature is raised above Tg.

The excess free volume may be estimated from the difference in thermal expansion coefficients $\alpha_{\mathrm{r}}$ and $\alpha_{\mathrm{g}}$ of a polymer above and below Tg, respectively [e.g., refs. $(8,9)$ ]:

$$
\frac{V_{o}-V_{r}}{V_{0}}=\left(a_{r}-a_{0}\right)(T g-\pi)
$$

\section{Dependence of Langmuir Capacity Constant, $c_{H}^{\prime}$, on the Excess Free Volume}

It has been suggested by Koros and Paul (10) that the Langmuir capacity constant, $c_{H}^{\prime}$, is related to the excess free volume and can be determined from the relation:

$$
c_{H}^{\prime}=\frac{V_{o}-V_{r}}{V_{o}} \rho^{*}=\left(a_{r}-a_{a}\right)\left(T g-7 \rho^{*}\right.
$$

where $\rho^{\circ}$ is the liquid molar density of the penetrant gas at temperature T. Equation (3) is based on the assumption that $c_{H}^{\prime}$ arises from the packing of penetrant gases into the excess (unrelaxed) volume of the glassy polymer $\left(\mathrm{V}_{\mathrm{g}}-\mathrm{V}_{\mathrm{r}}\right)$ with a liquid-like density (10). The molar density $\rho^{\bullet}$ is 


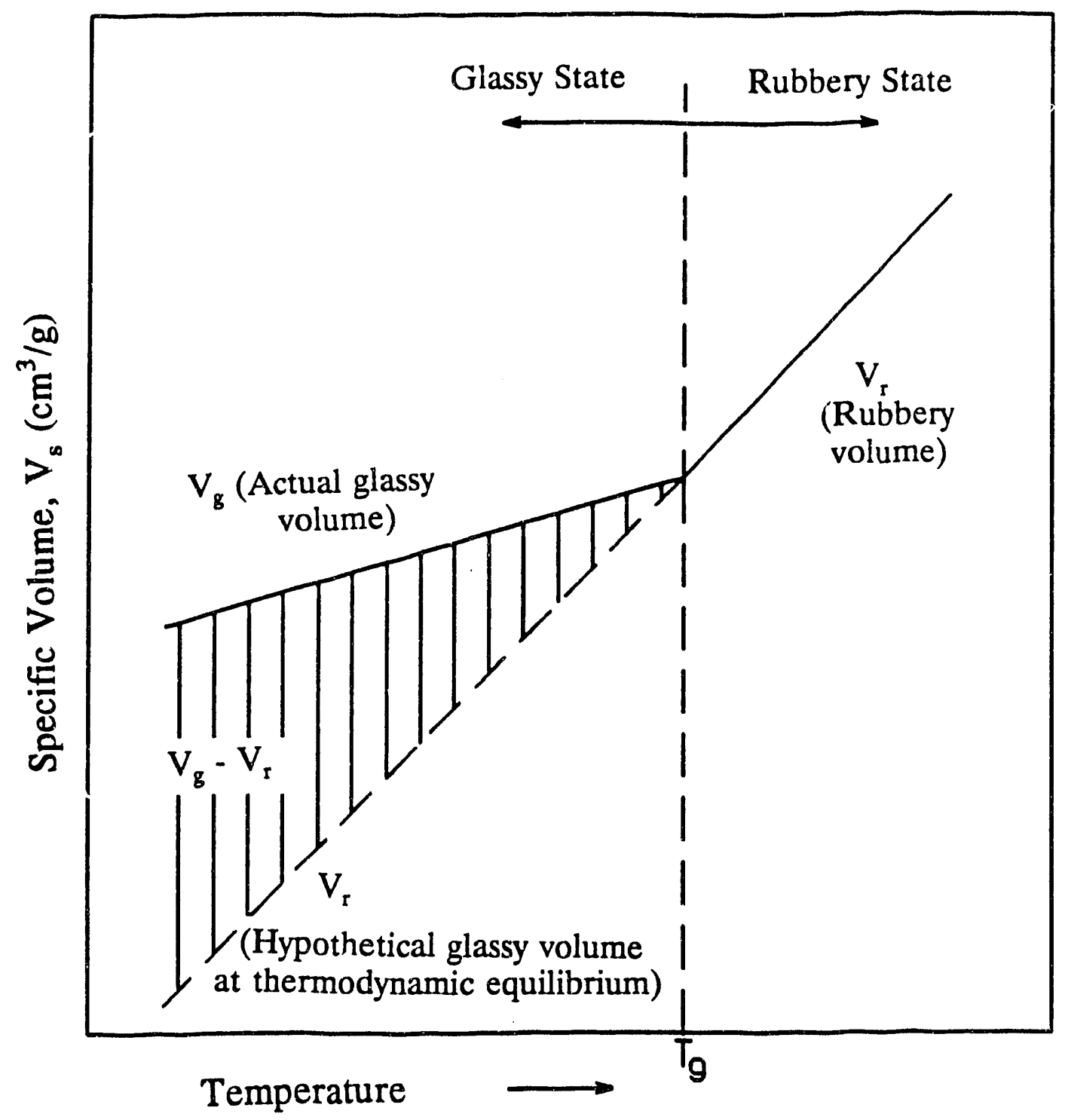

Figure 1. Plot of Specific Volume, $\mathrm{V}_{\mathrm{s}}$, of Polymers versus Temperature

The shaded area represents the "excess" (unrelaxed) free volume of the polymer in the glassy state.

$\mathrm{T}_{\mathrm{g}}=$ Glass-transition temperature 
a hypothetical quantity for supercritical gases.

The parameter $c_{H}^{\prime}$ decreases with increasing temperature and vanishes $\left(c_{H}^{\prime} \rightarrow 0\right) \mathrm{T} \rightarrow \mathrm{Tg}$. Equation (1) then reduces to Henr.'s law:

$$
c=k_{D} \cdot p
$$

i.e., the solubility isotherm becomes linear.

Toi, Morel, and Paul (11) have suggested that the values of $c_{H}^{\prime}$ for a given penetrant gas (i.e., for the same $\rho)$ should be proportional to $(\mathrm{Tg}-\mathrm{T})$, since $\Delta x\left(\equiv \alpha_{\mathrm{r}}-\alpha_{\mathrm{g}}\right)$ values are "quite similar for most polymers" (12). These investigators supported their suggestion with the data of Figure 2, which shows a plot of $c_{H}^{\prime}$ for $\mathrm{CO}_{2}$ in a number of glassy polymers versus the $\mathrm{Tg}$ of the polymers; all values of $c_{H}^{\prime}$ are for a constant temperature, $\mathrm{T}=35^{\circ} \mathrm{C}$. The plot is seen to be linear and includes the values of $c_{H}^{\prime}$ for poly(methyl methacrylate)(PMMA) and poly(ethyl methacrylate)(PEMA); $c_{H}^{\prime}$ is zero for $\mathrm{Tg}=33^{\circ} \mathrm{C}$, i.e., for $\mathrm{Tg} \approx \mathrm{T}$, cf. eqn. (3). It should be noted that the correlation of Figure 2 and eqn. (2) is entirely phenomenological, and implies that $\rho^{*}$ for a given penetrant gas has the same value in different polymers at a given temperature.

Simha and Boyer (13) have shown that $\Delta \alpha$ is not independent of $\mathrm{Tg}$, as assumed above, but that the following relationship holds true for many glassy and rubbery polymers:

$$
\Delta a \cdot T g=0.113
$$

as is illustrated in Figure 3; $\Delta \alpha$ is in units of $\mathrm{cm}^{3} / \mathrm{g} .{ }^{\circ} \mathrm{K}$, and $\mathrm{Tg}$ is in ${ }^{\circ} \mathrm{K}$. This figure also shows that the higher poly(alkyl methacrylates) have smaller $\Delta \alpha$ 's (i.e., smaller "excess" free 


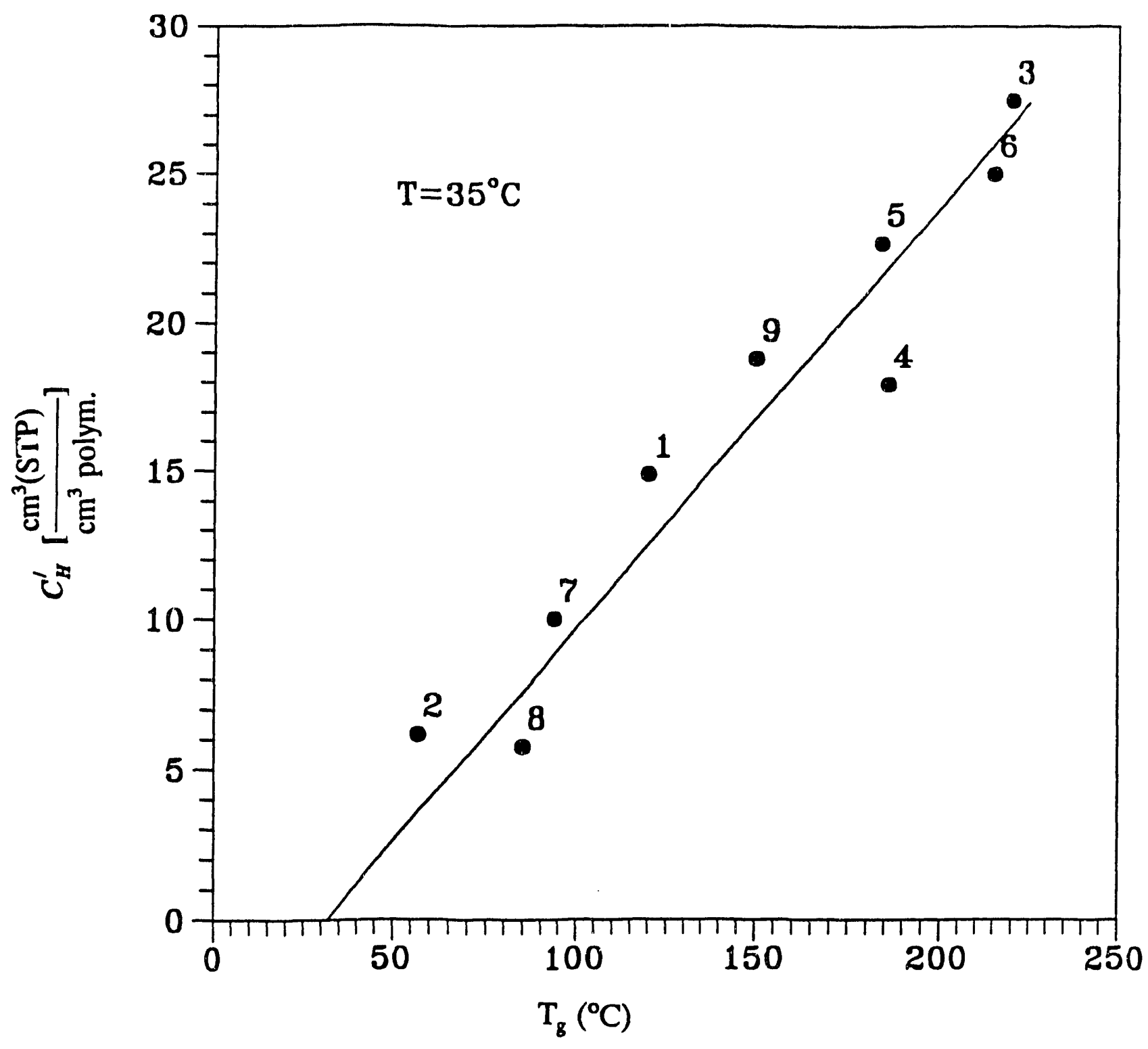

Figure 2. Correlation of Measured Values of the Langmuir Capacity Constant, $\mathrm{C}_{\mathrm{H}}{ }^{\prime}$, at $35^{\circ} \mathrm{C}$ with the Glass Transition Temperature of the Polymer.

Key: 1. Poly(methyl methacrylate); 2. Poly(ethyl methacrylate); 3. Poly(phenylene oxide);

4. Polysulfone; 5. Polyarylate; 6. Polyetherimide; 7. Polyhydroxyether;

8. Polyethylene terephthalate; 9. Polycarbonate. 


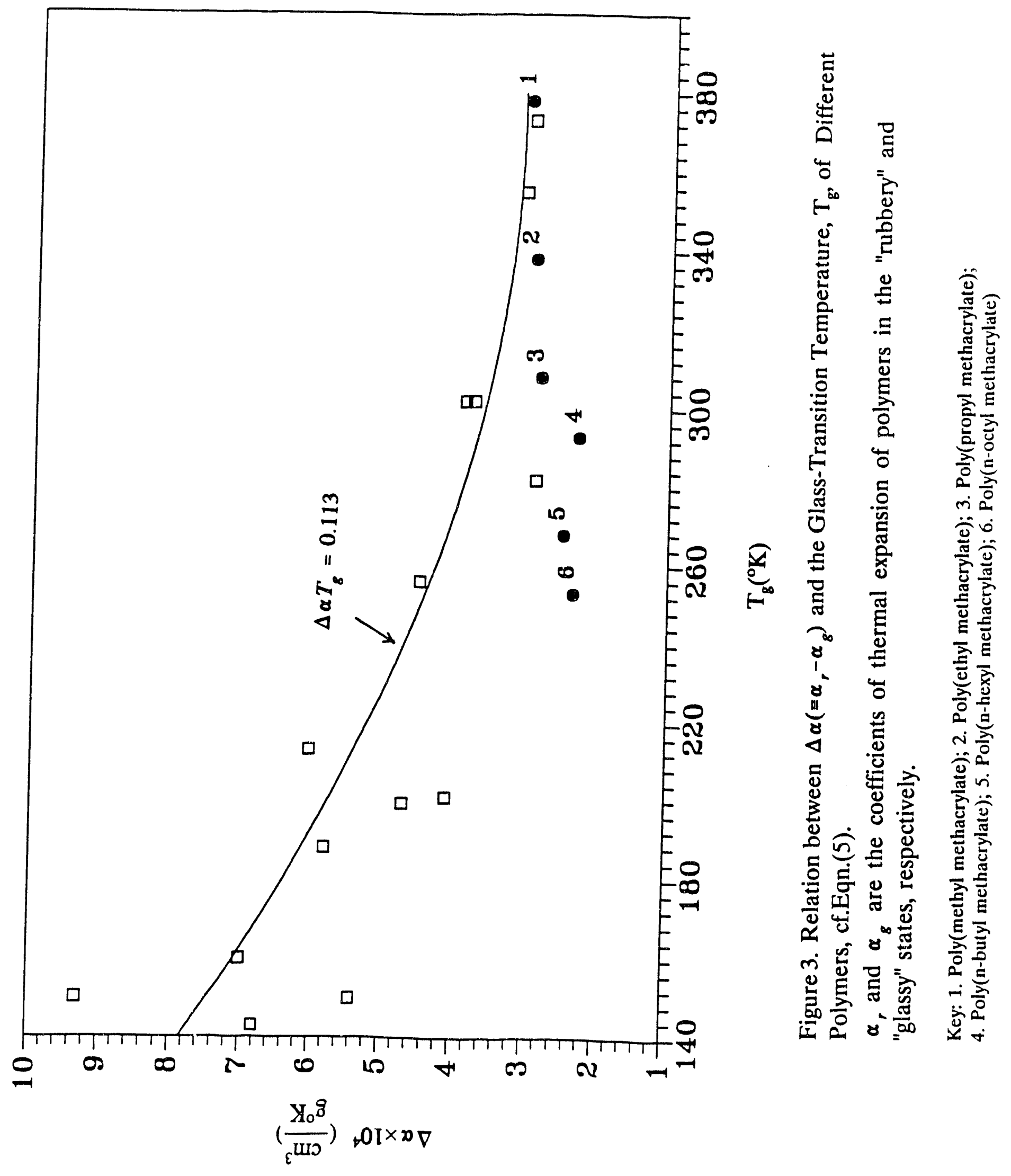


volumes) than other polymers with comparable Tg's. The smaller $\Delta \alpha$ 's of the poly(alkyl methacrylates) have been attributed to $\beta$ and $\gamma$ sub-Tg transitions caused by side-chain motions in these polymers (13). Tsubakiyama and Fujisaki have shown that for poly(alkyl methacrylates)

$$
\Delta a \cdot T g=k,
$$

where $\mathrm{k}$ decreases from 0.1066 for PMMA to 0.0706 for PnBMA.

Equations (3) and (6) yield:

$$
c_{H}^{\prime}=k\left(1-\frac{T}{T g}\right) \rho^{\prime \prime}
$$

where $\mathrm{T}$ and $\mathrm{Tg}$ are in ${ }^{\circ} \mathrm{K}$. Hence, a plot of $c_{H}^{\prime}$ versus $(1-\mathrm{T} / \mathrm{Tg})$ for a given penetrant gas in different poly(alkyl methacrylates) should be linear, provided that $\mathrm{k} \rho^{*}$ does not vary much with temperature and polymer structure. The validity of the above assumption has been tested by measuring the solubiiity of $\mathrm{CH}_{4}$ in poly(ethyl methacrylate)(PEMA) and poly(n-butyl methacrylate)(PnBMA) over a range of temperatures and at pressures up to $35 \mathrm{~atm}$.

\section{B. EXPERIMENTAL RESULTS}

PEMA and PnBMA have the following structural formulae:<smiles>CCOC(=O)C(C)(C)CC</smiles>

PEMA<smiles>CCCCC(C)(C)[Ge](C)(C)CC</smiles>

P $n$ BMA

The molecular weight, density, and glass-transition temperature of the polymers are listed 
in Table I. The polymers were used in the form of flat-sheet membranes, which were cast from solutions of the polymers in acetone.

The solubility of $\mathrm{CH}_{4}$ in PEMA $\left(\mathrm{Tg}=71^{\circ} \mathrm{C}\right)$ was measured at temperatures from 25 to $65^{\circ} \mathrm{C}$ and at pressures up to $35 \mathrm{~atm}$. The solubility of $\mathrm{CH}_{4}$ in $\mathrm{P} n \mathrm{BMA}\left(\mathrm{Tg}=71^{\circ} \mathrm{C}\right)$ was measured from -10 to $30^{\circ} \mathrm{C}$ and also up to $35 \mathrm{~atm}$. The solubility measurements were made by a volumetric technique which has been described by Shah, Hardy, and Stern (15). Other experimental details will be reported elsewhere (16).

The experimental results are presented in Figures 4 and 5, which show plots of the $\mathrm{CH}_{4}$ concentration (the $\mathrm{CH}_{4}$ solubility) in PEMA and $\mathrm{P} n \mathrm{BMA}$, respectively, as a function of the $\mathrm{CH}_{4}$ pressure, $\mathrm{p}$, at different temperatures under conditions of solution equilibrium. The solubility isotherms (i.e., the plots of $\mathrm{c}$ versus $\mathrm{p}$ ) at temperatures below the $\mathrm{Tg}$ of PEMA and PnBMA in Figure 4 and 5 are clearly of the dual-mode sorption type (1-5) and can be described by eqn. (1). The solubility isotherm for $\mathrm{CH}_{4}$ in $\mathrm{P} n \mathrm{BMA}$ at $30^{\circ} \mathrm{C}$ obeys Henry's law (i.e., is linear) because the temperature is above the $\mathrm{Tg}$ of the polymer, cf. eqn. (4).

The dual-mode sorption parameters $\mathrm{k}_{\mathrm{D}}, c_{H}^{\prime}$, and $\mathrm{b}$ in eqn. (1) were determined from nonlinear least-squares fits of this equation to the experimental solubility data. Values of the three parameters for $\mathrm{CH}_{4}$ in PEMA and PnBMA are listed in Tables II and III, respectively, and are seen to decrease with increasing temperature; as mentioned above, $c_{H}^{\prime} \rightarrow 0$ as $\mathrm{T} \rightarrow \mathrm{Tg}$.

The solubility of $\mathrm{CH}_{4}$ in PEMA has also been measured by Chiou and Paul (17), who found it to be about $25 \%$ higher than determined in the present study under comparable conditions. The values of the parameters $\mathrm{k}_{\mathrm{D}}, c_{H}^{\prime}$, and $\mathrm{b}$ obtained in the two studies are 


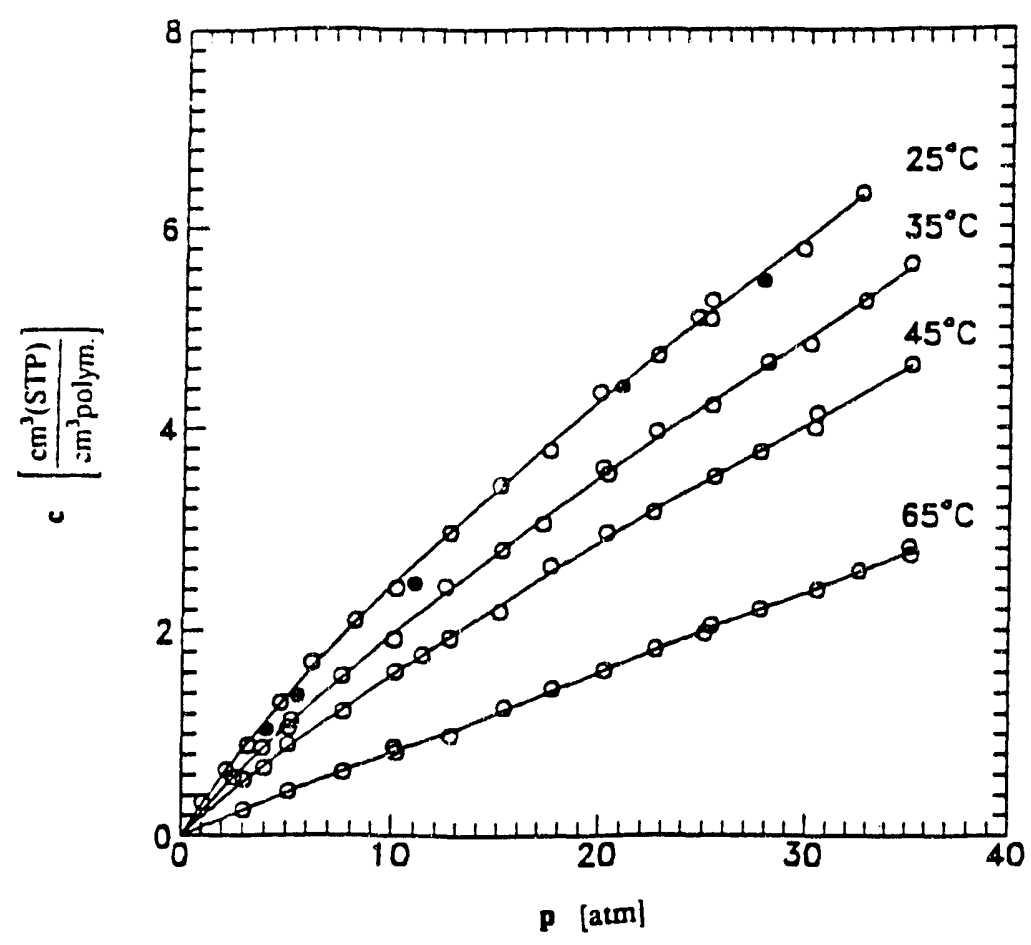

Figure 4. Plots of the $\mathrm{CH}_{4}$ concentration, $\mathrm{c}$, in Poly(Ethyl Methacrylate) (PEMA) as a Function of the $\mathrm{CH}_{4}$ Pressure, p, at Solution Equilibrium (Solubility Isotherms).

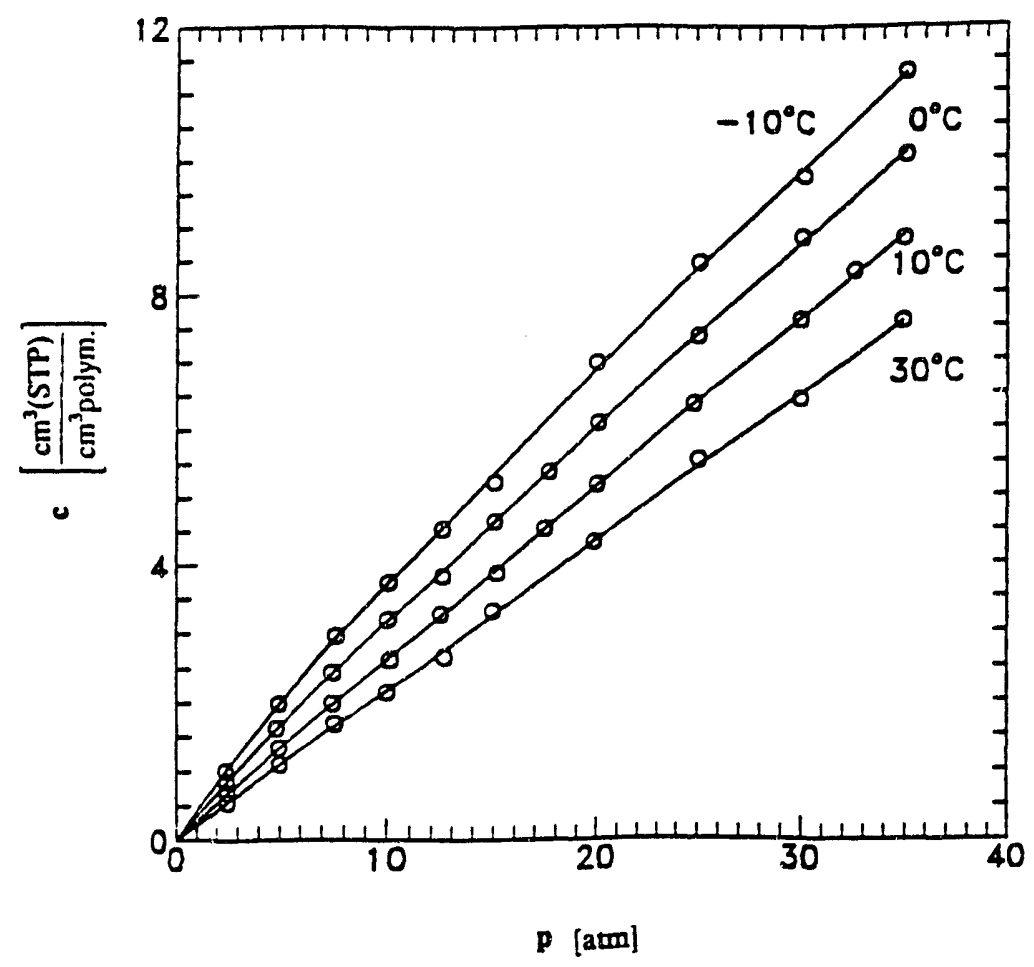

Figure 5. Plots of the $\mathrm{CH}_{4}$ concentration, $\mathrm{c}$, in Poly $(n$-Butyl Methacrylate) (PnBMA) as a Function of the $\mathrm{CH}_{4}$ Pressure, p, at Solution Equilibrium (Solubility Isotherms). 
compared in Table II. This table shows that the higher solubility values of Chiou and Paul are due mainly to their higher $\mathrm{k}_{\mathrm{D}}$ values; by contrast, the corresponding values of $c_{H}^{\prime}$ and b obtained in the two studies are in satisfactory agreement. Since the PEMA employed in the present study was the same as used by Chiou and Paul (Elvacite 2042, E.I. DuPont de Nemours \& Co.), the above difference in the $\mathrm{CH}_{4}$ solubility may be due to differences in the previous "history" of the polymer samples used.

The results of the solubility measurements are also presented in Figures 6 and 7 in the form of plots of the solubility coefficient $\mathrm{S}(\mathrm{c})(\equiv \mathrm{c} / \mathrm{p})$ versus the pressure, $\mathrm{p}$, for $\mathrm{CH}_{4}$ in PEMA and PnBMA, respectively. The plots of $S(c)$ versus $\mathrm{p}$ at temperatures below the $\mathrm{Tg}$ 's of the polymers are as expected from the dual-mode sorption model (1-6).

Figure 8 shows van't-Hoff-type semilogarithmic plots of $S(0)$ versus the reciprocal absolute temperature, 1/T, for $\mathrm{CH}_{4}$ in PEMA and PnBMA; $\mathrm{S}(0)$ is the solubility coefficient in the concentration limit $\mathrm{c} \rightarrow 0$. Figures $4-8$ show that the $\mathrm{CH}_{4}$ solubility decreases with increasing temperature, as is commonly found for light gases in polymers. Therefore, the heats of solutions are exothermic: $\Delta \mathrm{H}_{\mathrm{s}}=-6,500 \mathrm{cal} / \mathrm{mol}$ for $\mathrm{CH}_{4}$ in PEMA, and $\Delta \mathrm{H}_{\mathrm{s}}=-2,750 \mathrm{cal} / \mathrm{mol}$ for $\mathrm{CH}_{4}$ in $\mathrm{P} n \mathrm{BMA}$.

The solubility of $\mathrm{CH}_{4}$ in glassy PEMA $\left(\mathrm{Tg}=71^{\circ} \mathrm{C}\right)$ is higher than in glassy PnBMA (Tg $=21^{\circ} \mathrm{C}$ ) at comparable temperatures and pressures.

\section{DISCUSSION OF RESULTS}

The values of the Langmuir capacity constant $c_{H}^{\prime}$ obtained for $\mathrm{CH}_{4}$ in PEMA and PnBMA at different temperatures are plotted versus $1-\mathrm{T} / \mathrm{Tg}$ in Figure 9 in accurdance with eqn. (7); 


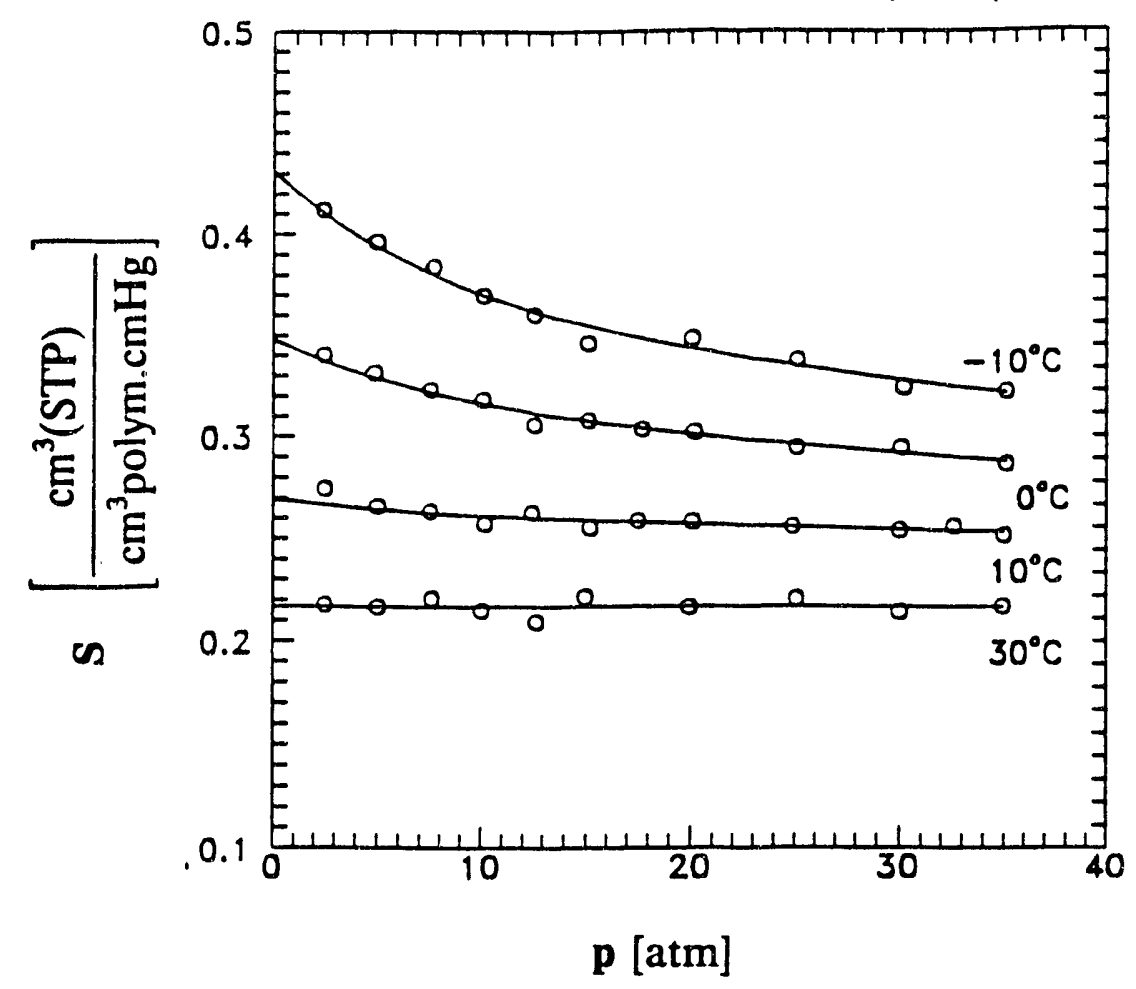

Figure 6. Plots of the Solubility Coefficient, $\mathrm{S}(\equiv \mathrm{c} / \mathrm{p})$, for $\mathrm{CH}_{4}$ in Poly(Ethyl Methacrylate) (PEMA) as a function of the $\mathrm{CH}_{4}$ Pressure, $\mathrm{p}$.

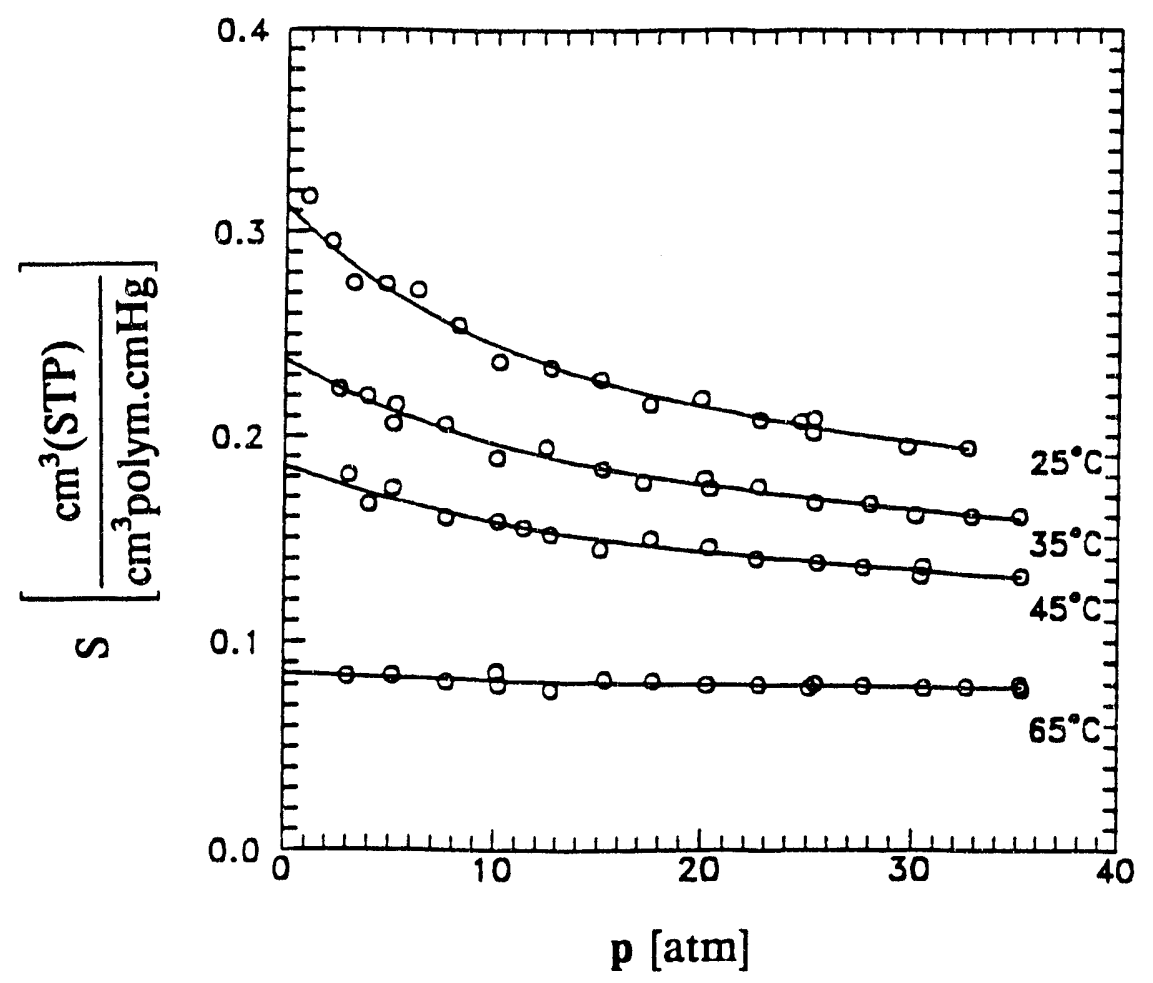

Figure 7. Plots of the Solubility Coefficient, $\mathrm{S}(\equiv \mathrm{c} / \mathrm{p})$, for $\mathrm{CH}_{4}$ in $\operatorname{Poly}(n$-Butyl Methacrylate) (PnBMA) as a function of the $\mathrm{CH}_{4}$ Pressure, $\mathrm{p}$. 


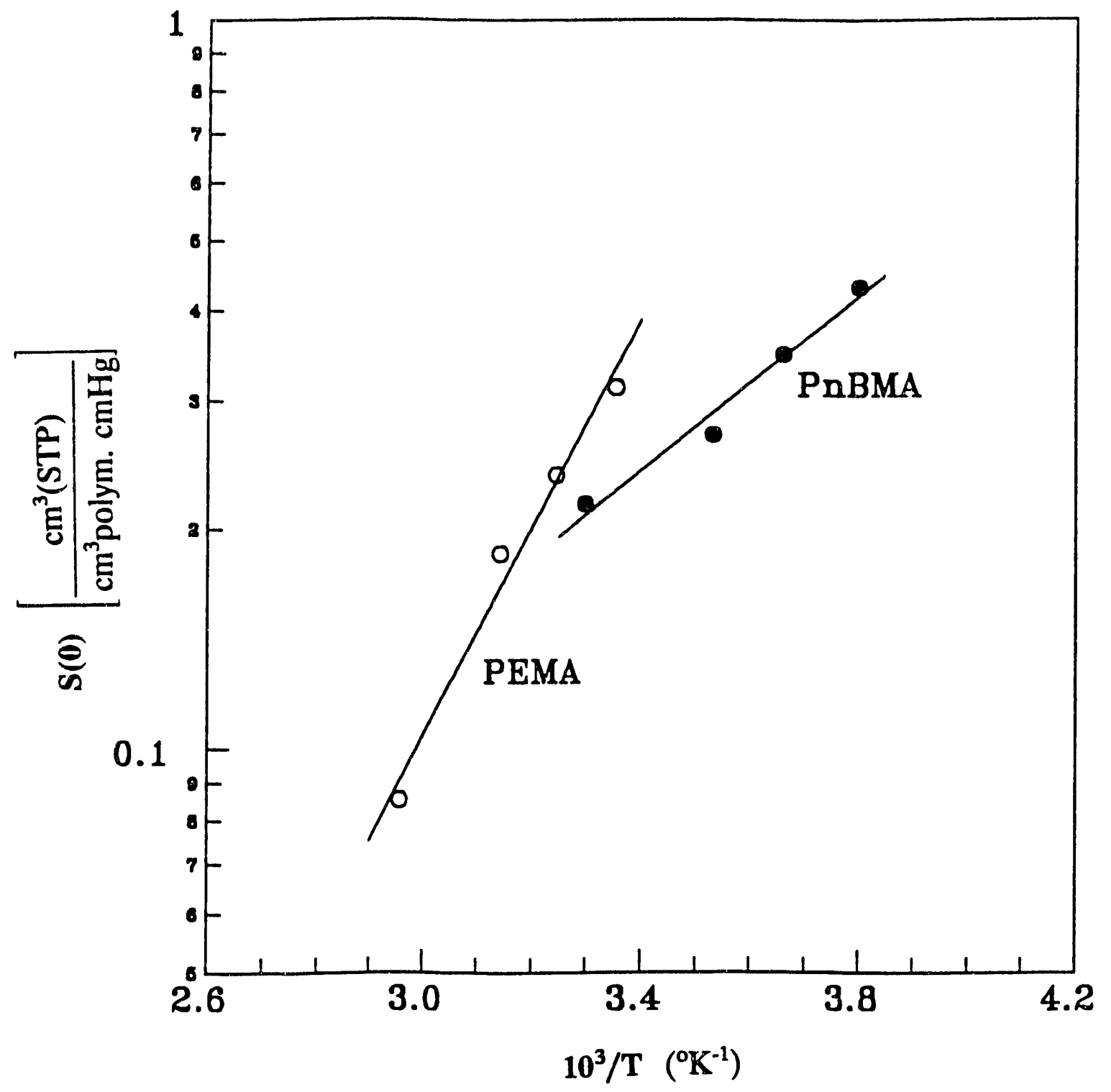

Figure 8. Plots of the Solubility Coefficient, $\mathrm{S}(0)$, for $\mathrm{CH}_{4}$ in Poly(Ethyl Methacrylate) (PEMA) and Poly ( $n$-Butyl Methacrylate) (PnBMA) in the Limit of Zero $\mathrm{CH}_{4}$ Concentration as a function of the Reciprocal Absolute Temperature, 1/T. 
$\mathrm{T}$ and $\mathrm{Tg}$ are, respectively, the temperature at which $c_{H}^{\prime}$ was measured, cf. Tables II and III, and the glass-transition temperature of the polymer, in ${ }^{\circ} \mathrm{K}$. The correlation is seen to be satisfactory (correlation coefficient: 0.271 ).

A plot of $c_{H}^{\prime}$ versus $\mathrm{Tg}-\mathrm{T}$, in accordance with eqn. (3), exhibits considerable more scatter (correlation coefficient: 0.626 ). This scatter can be reduced by plotting $c_{H}^{\prime}$ versus Tg [e.g., ref. (11)], but all $c_{H}^{\prime}$ values must then be for the same temperature, T. By contrast, the plot of $c_{H}^{\prime}$ versus $1-\mathrm{T} / \mathrm{Tg}$ [eqn. (7)] is applicable to data obtained at different temperatures.

The satisfactory correlations of $c_{H}^{\prime}$ with 1-T/Tg obtained for $\mathrm{CH}_{4}$ in PEMA and PnBMA via eqn. (7) is perhaps not unexpected, considering the chemical similarity of these two polymers. However, eqn. (7) is applicable to a much wider diversity of polymers. Thus, Figure 10 shows a plot of $c_{H}^{\prime}$ versus $1-\mathrm{T} / \mathrm{Tg}$ for $\mathrm{CH}_{4}$ in eight different polymers with $\mathrm{Tg}$ 's varying from $21^{\circ} \mathrm{C}$ [for poly $\left(n\right.$-butyl methacrylate)] to $215^{\circ} \mathrm{C}$ (polyetherimide); moreover, the $c_{H}^{\prime}$ values in Figure 10 were obtained at temperatures from $-10^{\circ}$ to $65^{\circ} \mathrm{C}$.

The scatter in some of the data in Figure 10 is due to the low solubility of $\mathrm{CH}_{4}$ in polymers, which may cause a significant error in the value of the parameter $c_{H}^{\prime}$ (as well as of $k_{D}$ and $b$ ). This is evidenced by the better fit of eqn. (7) to the experimental data obtained for $\mathrm{CO}_{2}$ in a variety of glassy polymers, cf. Figures 11 and 12 ; the solubility of $\mathrm{CO}_{2}$ in polymers is much higher than that of $\mathrm{CH}_{4}$, as is expected from the much higher critical temperature of the former gas $(15,18)$. 


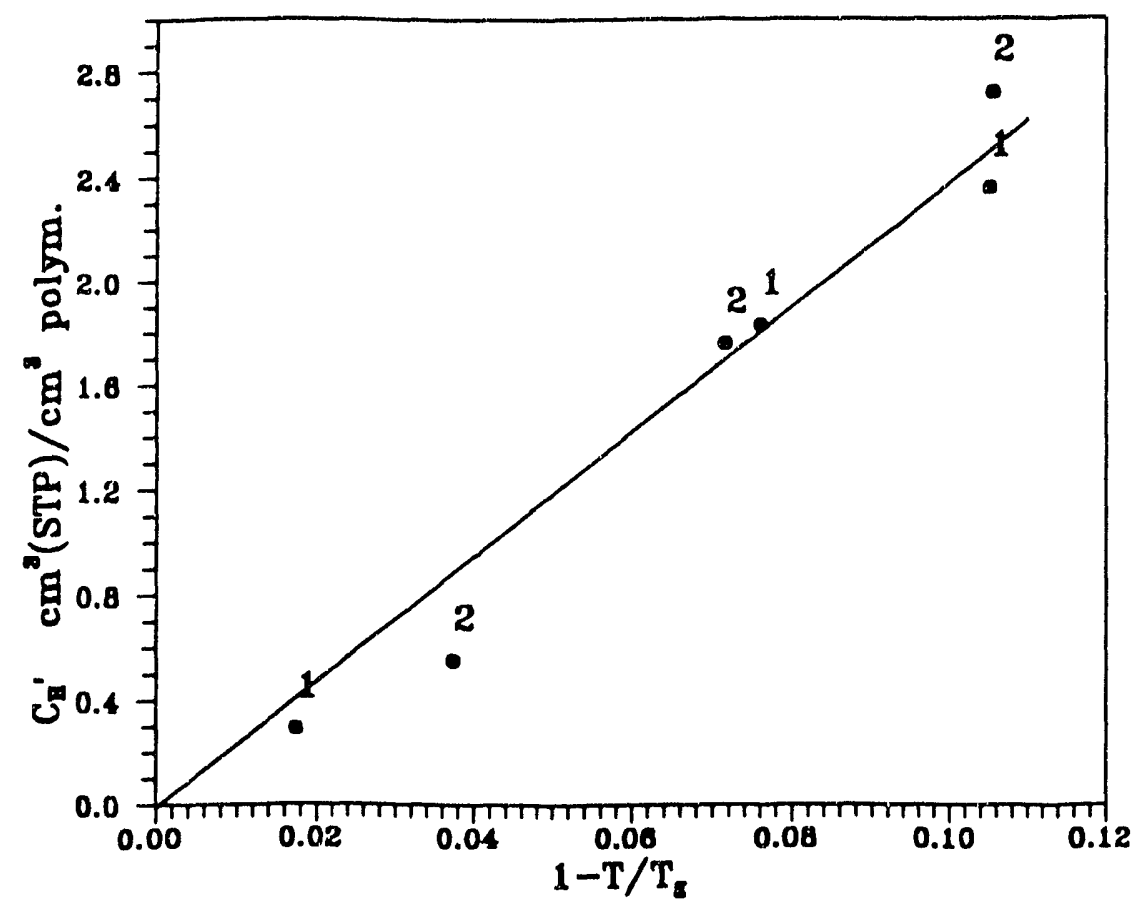

Figure 9. Plot of Langmuir Capacity Constant, $\mathrm{c}_{\mathrm{H}}^{\prime}$, versus $1-\mathrm{T} / \mathrm{T}$ for $\mathrm{CH}_{4}$ in Poly(alkyl methacrylates).

Key: 1. Poly(ethyl methacrylate); 2. Poly(n-Butyl methacrylate);

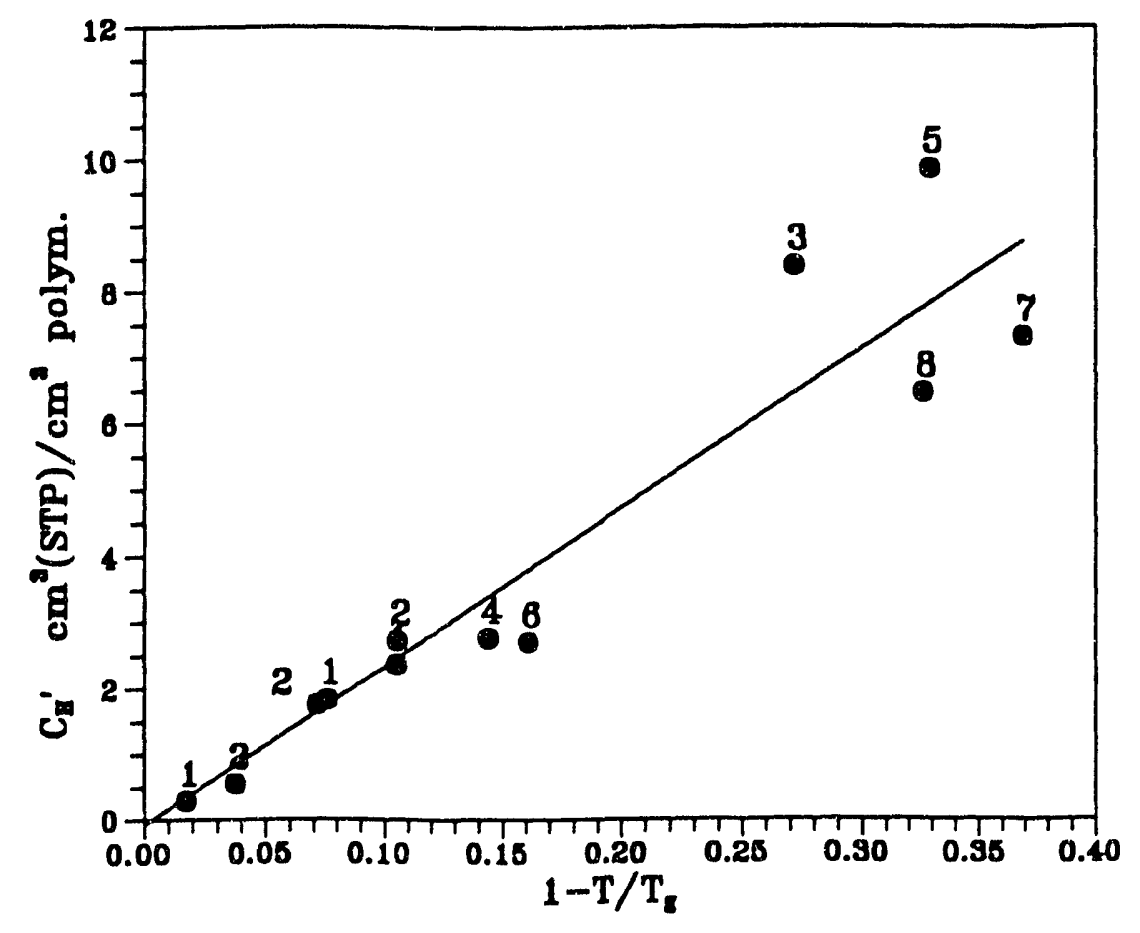

Figure 10. Plot of Langmuir Capacity Constant, $\mathrm{c}^{\prime}{ }_{\mathrm{Q}}$, versus $1-\mathrm{T} / \mathrm{T}_{\mathfrak{B}}$ for $\mathrm{CH}_{4}$ in Several Glassy Polymers.

Key: 1. Poly(ethyl methacrylate); 2. Poly(n-Butyl methacrylate); 3. Polycarbonate;

4. Isophthalic/terephthalic acid copolvmer: 5. Polvsulfone; $f$ Pnluhudmeneretha.. 
The linearity of the plot of $c_{H}^{\prime}$ versus $\mathrm{Tg}$ (at constant $\mathrm{T}$ ), cf. eqn. (3), and of the more general plots of $c_{H}^{\prime}$ versus $1-\mathrm{T} / \mathrm{Tg}$, cf., eqn. (7), implies that $c_{H}^{\prime}$ depends primarily on $\mathrm{Tg}$ for many glassy polymers. $\mathrm{Tg}$ is a measure of the stiffness of polymer chains. Referring to eqn. (7), the fact that $c_{H}^{\prime}$ correlates with $1-\mathrm{T} / \mathrm{Tg}$ for such a diversity of polymers and for different temperatures indicates that the product $\mathrm{k}^{\circ}$ is essentially constant, at least for the gas/polymer systems and temperatures investigated, cf. Figures 10 and 12. Parameter $\mathrm{k}$ is taken to be constant; $\rho^{\bullet}$ is assumed to be the liquid molar density of the penetrant gas and should be dependent on the temperature, cf. Section A-3. However, values of $\rho^{*}$ are available only for temperatures below the critical temperatures of the penetrant gas, e.g., for $\mathrm{CO}_{2}$ below $30.9^{\circ} \mathrm{C}$. It has been suggested that the values of $\rho^{*}$ proposed by Prausnitz and Shair (19) for supercritical gases in a hypothetical liquid state could be used in conjunction with eqns. (3) and (7), but these values do not yield $c_{H}^{\prime}$ values consistent with the experimental results.

Finally, it should be noted that the correlation of $c_{H}^{\prime}$ with $1-\mathrm{T} / \mathrm{Tg}$ for various polymers includes PEMA and P $n$ BMA, in spite of the lower $\Delta \alpha\left(\equiv \alpha_{\mathrm{r}}-\alpha_{\mathrm{g}}\right)$ (lower $\left.\mathrm{k}\right)$ values of the poly(alkyl methacrylates). This result may be due to the fact that, as mentioned earlier, the poly(alkyl methacrylates) exhibit sub-Tg transitions, and hence additional free volume is created below their $\mathrm{Tg}$. Simha and Boyer (13) have suggested that the relevant quantity in eqn. (5) should be $\Delta \alpha^{\prime}\left(\equiv \alpha_{\mathrm{r}}-\alpha_{\text {gos }}^{\prime}\right)$, where $\alpha_{\text {oos }}^{\prime} \leqq \alpha_{\mathrm{g}}$ represents the thermal expansion coefficient of the glassy polymer below the second sub-Tg transition. The value of $\Delta \alpha^{\prime}$ for PEMA and P $n$ BMA, and probably also of the higher poly(alkyl methacrylates), is then consistent with that of other glassy polymers.

The solubility of $\mathrm{C}_{2} \mathrm{H}_{6}$ in $\mathrm{P} n \mathrm{BMA}$ has also been measured at temperatures from $-8.5^{\circ}$ to $35^{\circ} \mathrm{C}$ and at pressures up to about $33 \mathrm{~atm}$. The results of these measurements are presented in 


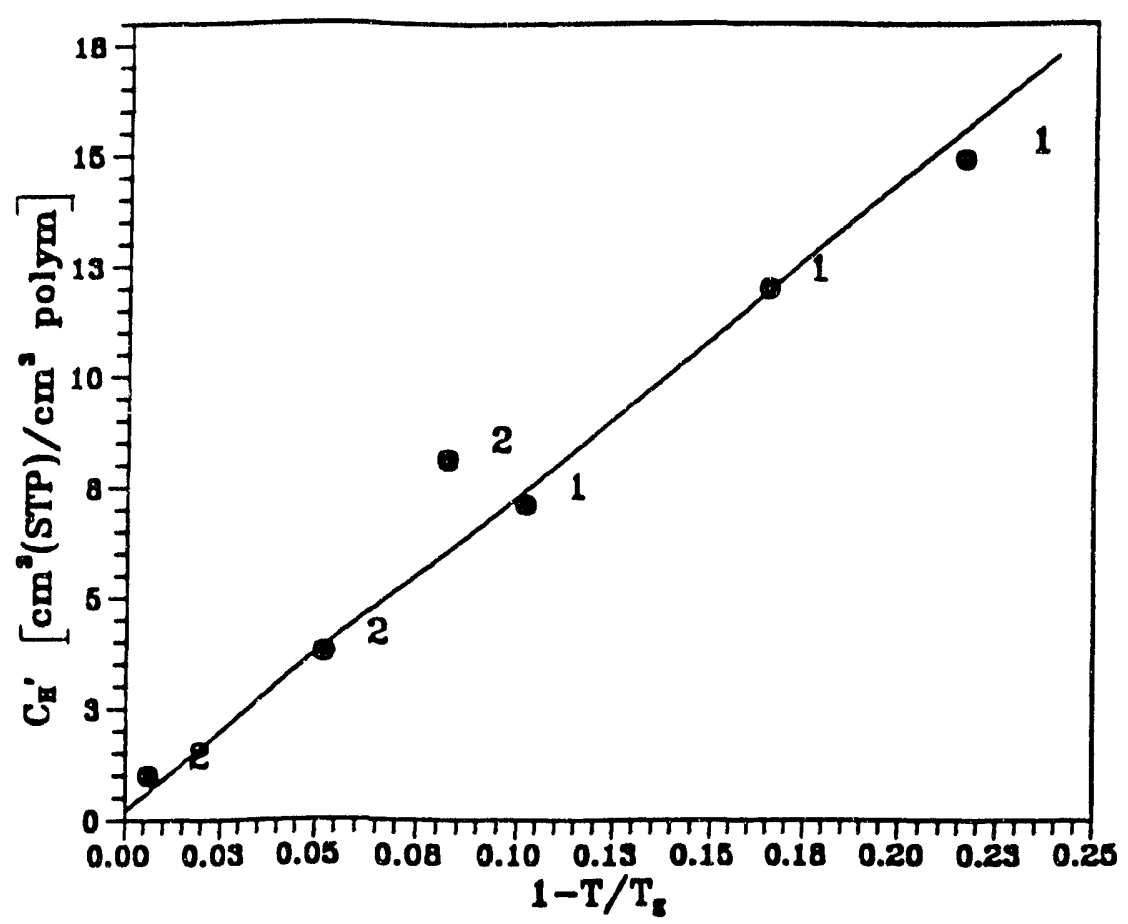

Figure 11. Plot of Langmuir Capacity Constant, $c_{H}^{\prime}$, versus $1-T / T_{g}$ for $\mathrm{CO}_{2}$ in Poly(alkyl methacrylates).

Key: 1. Poly(methyl methacrylate); 2 Poly(ethyl methacryiate)

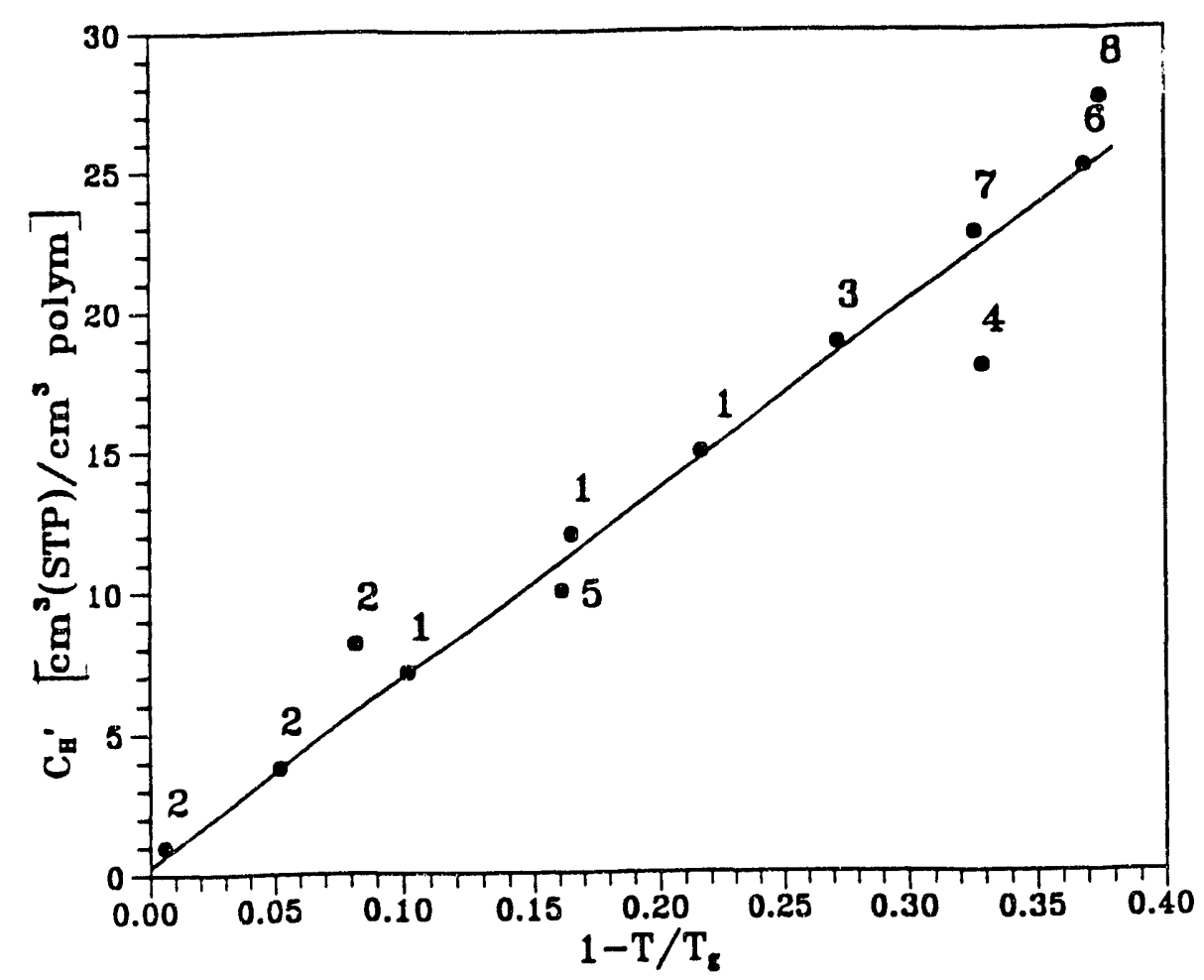

Figure 12. Plot of Langmuir Capacity Constant, $c_{H}^{\prime}$, versus $1-T / T_{g}$ for $\mathrm{CO}_{2}$ in Several Glassy Polymers.

Kev: 1. Poly(methyl methacrylate); 2. Poly(ethyl methacrylate); 3. Polycarbonate; 
Figures 13 and 14 in the form of isothermal plots of the $\mathrm{C}_{2} \mathrm{H}_{6}$ solubility, $\mathrm{c}$, versus the pressure, $p$, and of the solubility coefficient, $S(\equiv c / p)$ versus $p$, respectively. These plots are not of the dual-mode sorption type, except at $-8.5^{\circ} \mathrm{C}$ and at the lowist pressures, and indicate that $\mathrm{P} n \mathrm{BMA}$ is markedly plasticized by $\mathrm{C}_{2} \mathrm{H}_{6}$, probably because of the low $\mathrm{Tg}$ of this polymer. Therefore, these data must be treated by a modified dual-mode sorption relation, cf. Part I, eqn. 14 . 


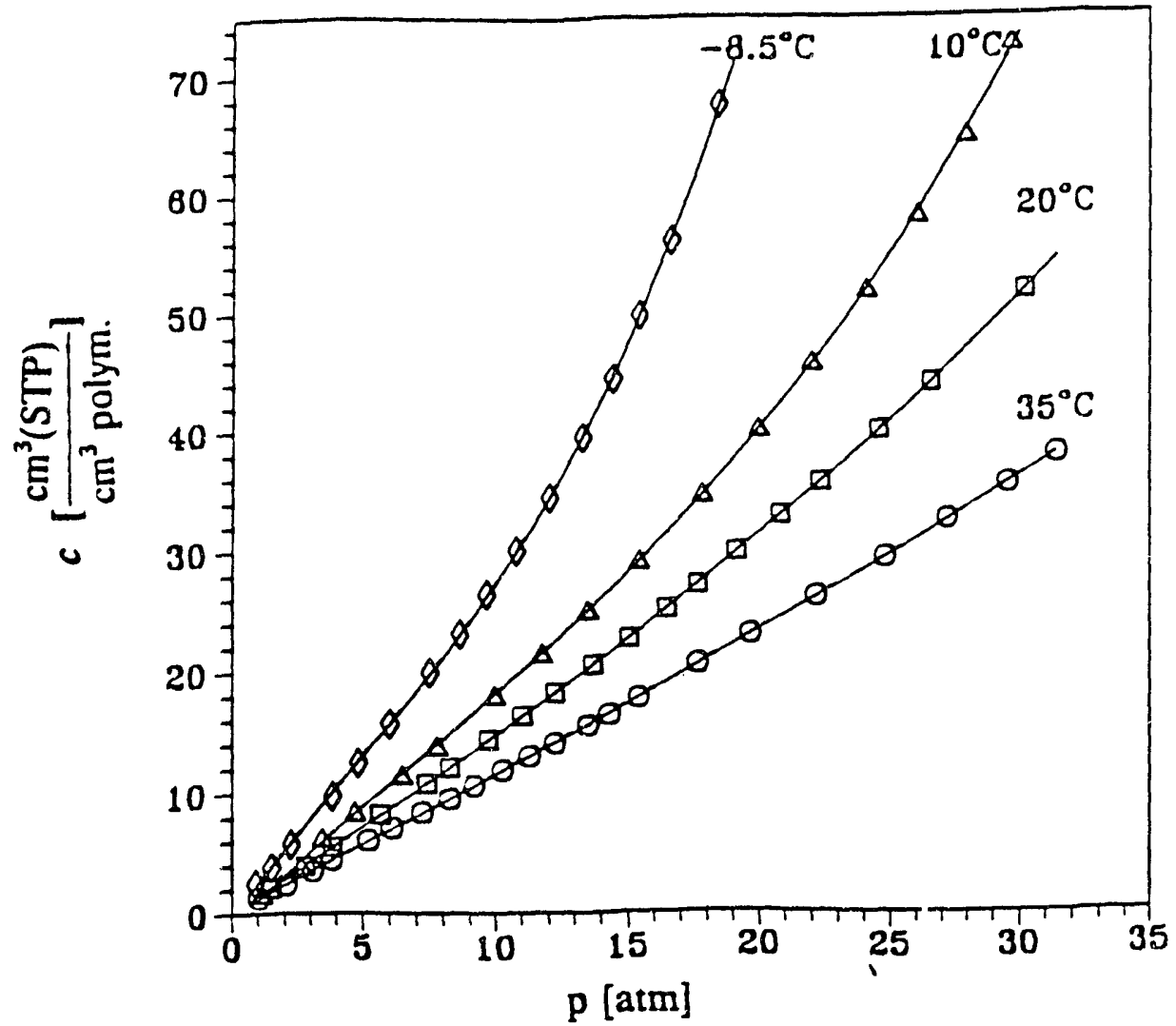

Figure 13. Plots of $\mathrm{C}_{2} \mathrm{H}_{6}$ concentration, c, in Poly(n-Butyl Methacrylate)(PnBMA) as a Function of $\mathrm{C}_{2} \mathrm{H}_{6}$ Pressure, $\mathrm{p}$ at Solution Equilibrium (Solubility Isotherms)

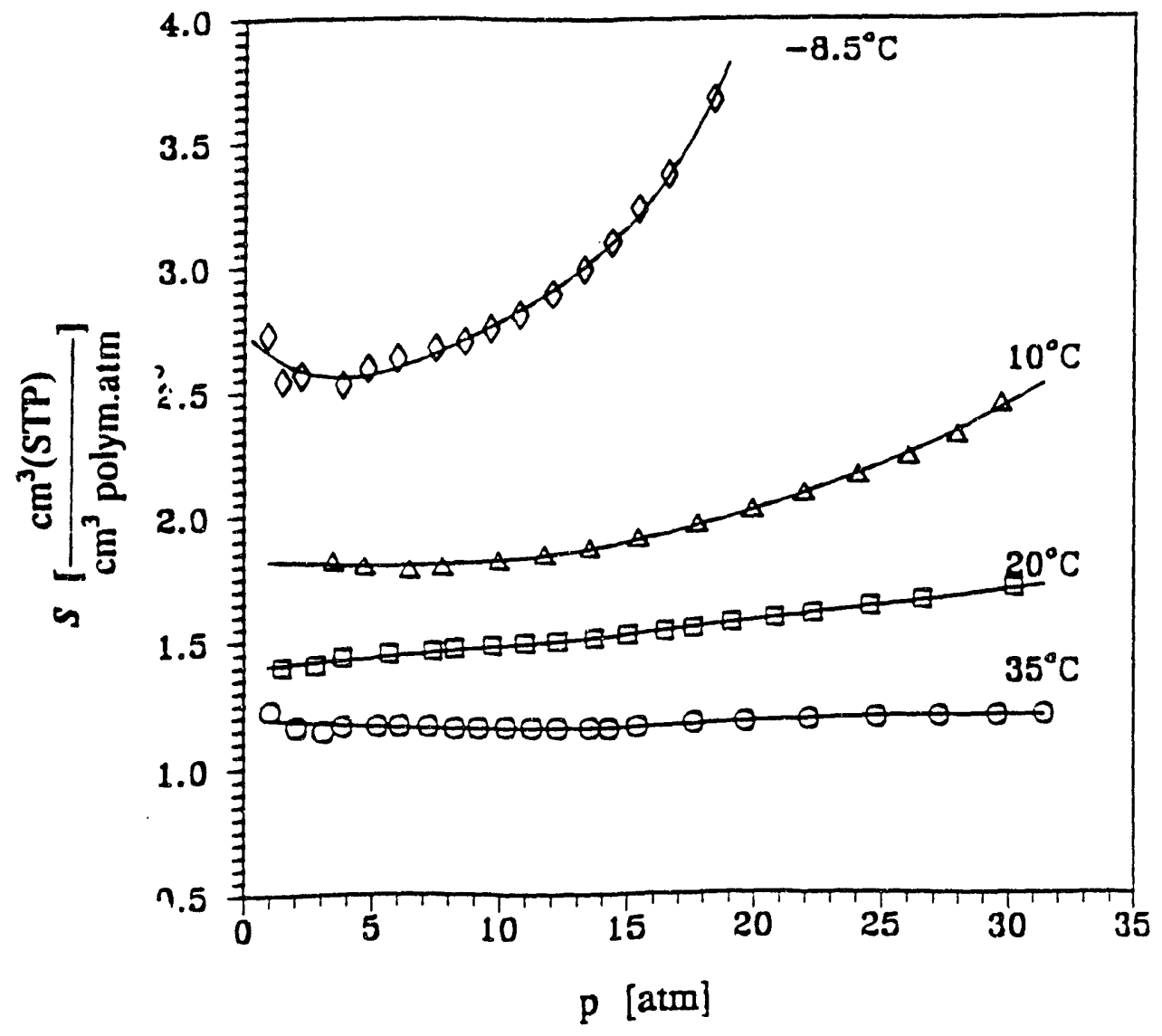

Figure 14. Plots of Solubility Coefficient, $\mathrm{S}(\equiv c / p)$, for $\mathrm{C}_{2} \mathrm{H}_{6}$ in Poly(n-Butyl Methacrylate)(PnBMA) as a Function of $\mathrm{C}_{2} \mathrm{H}_{6}$ Pressure 


\section{REFERENCES}

1. D.R. Paul, Ber. Bunsenges. Phys. Chem., $\underline{83}, 294$ (1979).

2. H.L. Frisch and S.A. Stern, Crit. Revs. Solid State and Mat. Sci., 11(2), 123 (1987), CRC Press, Boca Raton, FL.

3. W.J. Koros and R.T. Chern, Chapt. 20 in "Handbook of Separation Process Technology", R.W. Rousseau, Ed., Wiley-Interscience, New York, 1987, pp. 862-953.

4. W.R. Vieth, "Membrane Systems: Analysis and Design", Hanser Publishers, New York, 1988.

5. S.A. Stern and S. Trohalaki, Chapt. 2 in "Barrier Polymers and Structures", W.J Koros, Ed., ACS Symposium Series 423, American Chemical Society, Washington, DC, 1990. pp. 22-59.

6. S.A. Stern, in "Synthetic Membranes", M.B. Chenoweth, Ed., MMI Press Symposium Series, Vol. 5, Harwood Academic Publishers, New York, 1986, pp. 1-37.

7. W.J. Koros, G.N. Smith, and V. Stannett, J. Appl. Polym. Sci., 26, 159 (1981).

8. W.J. Koros, A.H. Chan, and D.R. Paul, J. Membrane Sci., 2, 165 (1977).

9. K. Toi, G. Morel, and D.R. Paul, J. Appl. Polym. Sci., 27, 2997 (1982).

10. W.J. Koros and D.R. Paul, J. Polym. Sci., Polym. Phys. Ed., 16, 1947 (1978).

11. K. Toi, G. Morel, and D.R. Paul, J. Appl. Polym. Sci., 27, 2997 (1982).

12. S.C. Sharma, L. Mandelkern, and F.C. Stehling, Polym. Lett., 10, 345 (1972).

13. R. Simha and R.F. Boyer, J. Chem. Phys. 37, 1003 (1962).

14. K. Tsubakiyama and S. Fujisaki, Polym. Lett., 10, 345 (1972).

15. V.M. Shah, B.J. Hardy, and S.A. Stern, J. Polym. Sci.: Part B: Polym. Phys., 24, 2033 (1986).

16. J.H. Kim and S.A. Stern, In preparation.

17. J.S. Chiou and D.R. Paul, J. Membrane Sci., 45, 167 (1989).

18. S.A. Stern and S.-P. Shiah, Molec. Pharmacol. $\underline{19}, 56$ (1981).

19. J.M. Prausnitz and F.H. Shair, AIChE Journal, 7,682 (1961). 
TABLE I

Physical Properties of PEMA and P $n$ BMA

\begin{tabular}{||c|c|c|c||}
\hline Polymer & $\begin{array}{c}\text { Molecular Weight, } \\
(\mathbf{g} / \mathbf{m o l})\end{array}$ & $\begin{array}{c}\text { Density }{ }^{(\mathbf{(})} \\
\left(\mathbf{g} / \mathbf{c m}^{\mathbf{3}}\right)\end{array}$ & $\begin{array}{c}\text { Glass-Transition } \\
\text { Temperature, } \\
\left({ }^{(\mathbf{b})}\right.\end{array}$ \\
\hline PEMA & 438,000 & 1.1258 & 71 \\
\hline PnBMA & 100,000 & 1.0462 & 21 \\
\hline
\end{tabular}

(a) Measured by means of a density-gradient column containing a $\mathrm{ZnCl}_{2}$ solution

(b) Measured by DSC with a heating rate of $10^{\circ} \mathrm{C} / \mathrm{min}$.

\section{TABLE II}

Dual-mode Sorption Parameters for $\mathrm{CH}_{4}$ in PEMA

\begin{tabular}{||c|c|c|c||c|c|c||}
\hline \multirow{2}{*}{$\mathbf{T}\left({ }^{\circ} \mathbf{C}\right)$} & \multicolumn{3}{|c||}{ This work } & \multicolumn{3}{c||}{ Chiou and Paul } \\
\cline { 2 - 7 } & $\mathbf{k}_{\mathbf{D}}$ & $c_{H}^{\prime}$ & $\mathbf{b}$ & $\mathbf{k}_{\mathbf{D}}$ & $c_{H}^{\prime}$ & $\mathbf{b}$ \\
\hline 25 & 0.1358 & 2.83 & 0.0626 & 0.183 & 2.87 & 0.0677 \\
\hline 35 & 0.1158 & 2.36 & 0.0517 & 0.165 & 2.24 & 0.0536 \\
\hline 45 & 0.0989 & 1.83 & 0.0474 & 0.144 & 1.87 & 0.0422 \\
\hline 65 & 0.0738 & 0.29 & 0.0397 & - & - & - \\
\hline
\end{tabular}

Units: $\mathrm{k}_{\mathrm{D}}\left[\mathrm{cm}^{3}(\mathrm{STP}) / \mathrm{cm}^{3}\right.$ polym. atm]; $c_{H}^{\prime}\left[\mathrm{cm}^{3}(\mathrm{STP}) / \mathrm{cm}^{3}\right.$ polym.]; b (atm. $\left.{ }^{-1}\right)$

TABLE III

Dual-mode Sorption Parameters for $\mathrm{CH}_{4}$ in PnBMA

\begin{tabular}{|c|c|c|c|}
\hline $\mathbf{T}\left({ }^{\circ} \mathbf{C}\right)$ & $\mathbf{k}_{\mathbf{D}}$ & $\mathbf{c}_{\mathbf{H}}^{\prime}$ & $\mathbf{b}$ \\
\hline-10 & 0.2689 & 2.72 & 0.0596 \\
\hline 0 & 0.2554 & 1.76 & 0.0526 \\
\hline 10 & 0.2436 & 0.55 & 0.0468 \\
\hline 30 & 0.2170 & - & - \\
\hline
\end{tabular}

Units: $\mathrm{k}_{\mathrm{D}}\left[\mathrm{cm}^{3}(\mathrm{STP}) / \mathrm{cm}^{3}\right.$ polym. atm.]; $c_{H}^{\prime}\left[\mathrm{cm}^{3}(\mathrm{STP}) / \mathrm{cm}^{3}\right.$ polym.]; b(atm $\left.{ }^{-1}\right)$ 


\section{PUBLICATIONS RESULTING FROM STUDIES SPONSORED BY THE OFFICE OF BASIC ENERGY SCIENCES, U.S. DEPT. OF ENERGY}

1. Stern, S.A. and Leone, S.M., "The Separation of Krypton and Xenon by Selective Permeation", AIChE J., 26, 881-890 (1980).

2. Stern, S.A. and Wang S.-C., "Permeation Cascades for the Separation of Krypton and Xenon from Nuclear Reactor Atmospheres", AIChE J., 26, 891-901 (1980).

3. Stern, S.A. and Saxena, V., "Concentration-Dependent Transport of Gases and Vapors in Glassy Polymers", J. Membrane Sci., 7, 47-59 (1980).

4. Stern, S.A. and Frisch, H.L., "Selective Permeation of Gases through Polymers", Ann. Revs. Mater. Sci., 11, 523-50 (1981) (Invited review article).

5. Stern, S.A. and Kulkarni, S.S., "Solubility of Methane in Cellulose Acetate. Conditioning Effect of Carbon Dioxide", J. Membrane Sci., 10, 235-251 (1982).

6. Saxena, V. and Stern, S.A., "Concentration-Dependent Transport of Gases and Vapors in Glassy Polymers. II. Organic Vapors in Ethyl Cellulose", J. Membrane Sci., 12, 65-85 (1982).

7. Mauze, G.R. and Stern, S.A., "The Solution and Transport of Water Vapor in Poly(Acrylonitrile)", J. Membrane Sci., 12, 51-64 (1982).

8. Kulkarni, S.S. and Stern, S.A., "Diffusion of $\mathrm{CO}_{2}, \mathrm{CH}_{4}, \mathrm{C}_{2} \mathrm{H}_{4}$, and $\mathrm{C}_{3} \mathrm{H}_{8}$ in Polyethylene at Elevated Pressures", J. Polym. Sci., Polym. Phys. Ed., 21, 441-465 (1983).

9. Stern, S.A., Kulkami, S.S., and Frisch, H.L., "Tests of a Free-Volume Model of Gas Permeation through Polymer Membranes. I. Pure $\mathrm{CO}_{2}, \mathrm{CH}_{4}, \mathrm{C}_{2} \mathrm{H}_{4}$, and $\mathrm{C}_{3} \mathrm{H}_{8}$ in Polyethylene", J. Polym. Sci., Polym. Phys. Ed., 21, 467-481 (1983).

10. Frisch, H.L. and Stern, S.A., "The Diffusion of Small Molecules in Polymers", Crit. Revs. Solid State and Mat. Sci., 11(2), 123-187 (1983), CRC Press, Boca Raton, FL (Invited Review Paper).

11. Stern, S.A., Mauze, G.R., and Frisch, H.L., "Tests of a Free-Volume Model for the Permeation of Gas Mixtures through Polymer Membranes. $\mathrm{CO}_{2}-\mathrm{C}_{2} \mathrm{H}_{4}, \mathrm{CO}_{2}-\mathrm{C}_{3} \mathrm{H}_{8}$, and $\mathrm{C}_{2} \mathrm{H}_{4}-$ $\mathrm{C}_{3} \mathrm{H}_{8}$ Mixtures in Polyethylene", J. Polym. Sci., Polym. Phys. Ed., 21, 1275-1298 (1983).

12. Mauze, G.R. and Stern, S.A., "Dual-Mode Solution and Transport of Water in Poly(Acrylonitrile)", Polym. Eng. Sci., 23, 548-555 (1983). 
13. Mauze, G.R. and Stem, S.A., "The Dual-Mode Solution of Vinyl Chloride Monomer in Glassy Poly(Vinyl Chloride)", J. Membrane Sci., 18, 99-109 (1984).

14. Stern, S.A., Sampat, S.R., and Kulkarni, S.S., "Tests of a Free-Volume Model of Gas Permeation through Polymer Membranes. II. Pure Ar, $\mathrm{SF}_{6}, \mathrm{CF}_{4}$, and $\mathrm{C}_{2} \mathrm{H}_{2} \mathrm{~F}_{2}$ in Polyethylene", J. Polym. Sci.: Part B: Polym. Phys., 24, 2149-2166 (1986).

15. Stern, S.A., Vakil, U.M., and Mauze, G.R., "Solution and Transport of Light Gases in Poly(n-Butyl Methacrylate) in the Glass-Transition Region. I. Absorption-Desorption Measurements", J. Polym. Sci.: Part B: Polym. Phys., 27(2), 405-429 (1989).

16. Zhou, S. and Stern, S.A., "The Effect of Plasticization on the Transport of Gases in and through Glassy Polymers", J. Polym. Sci.: Part B: Polym. Phys., 27, 205-222 (1989).

17. Subramanian, S. and Stern, S.A., "Dual-Mode Sorption Kinetics of Gases in Glassy Polymers", J. Polym. Sci.: Part B: Polym. Phys., 27, 1209-1220 (1989).

18. Stern, S.A., Zhou, S., Arauz-Lara, J.L., and Ware, B.R., "Evidence of Dual-ModDiffusion of Small Molecules in Poly(1-Trimethylsilyl-1-Propyne) from Fluorescence Photobleaching Recovery", J. Polym. Sci.: Part C: Polym. Letiers, 27, 427-431 (1989).

19. Stern, S.A. and Trohalaki, S., "Fundamentals of Gas Diffusion in Rubbery and Glassy Polymers", Chapt. 2 in "Barrier Polymers and Structures", W.J. Kuros, Ed., ACS Symposium Series 423, American Chemical Society, Wash:işın, D.C., 1990, pp. 22-59.

20. Mi, Y., Zhou, S., and Stern, S.A., "A New Representation of Gas Solubility in Glassy Polymers Based on a Concentration-Temperature Superposition Principle", Macromolecules, 24, 2361-2367 (1991).

21. Mi, Y., Trohalaki, S., and Stern, S.A., "Dependence of Gas Permeability of Some Polyimide Isomers on their Intrasegmental Mobility", Accepted for publication in J. Membrane Sci.

22. Stern, S.A., Charati, S., and Onurval, N., "Gas Solubility in Biological Media: A Simple Correlation". Accepted for publication in J. Membrane Sci.

23. Itoh, K. and Stern, S.A., "The Solution and Transport of Gases in Poly(n-Butyl Methacrylate) in the Glass-Transition Region. II. Time-Lag Measurements", In preparation.

24. Kim, J.-H. and Stern, S.A., "The Solubility of Methane in Poly(Alkyl Methacrylates) at Elevated Pressures", In preparation.

25. Mi., Y., Stern, S.A., and Zhou, S., "Representation of Diffusivity of Plasticizing Gases in Glassy Polymers by a Concentration-Temperature Superposition Principle", In preparation. 
DATE FILMED $2 / 2 / 93$ 
